Estudios Constitucionales, Año 10, No 1, 2012, pp. 201 - 244.

ISSN 0718-0195

Centro de Estudios Constitucionales de Chile Universidad de Talca

"Hacia una progresiva constitucionalización

del poder sancionador del Consejo de Seguridad de la ONU"

Dr. Luis I. Gordillo Pérez

\title{
HACIA UNA PROGRESIVA CONSTITUCIONALIZACIÓN DEL PODER SANCIONADOR DEL CONSEJO DE SEGURIDAD DE LA ONU $\left(^{(}\right)$
}

\author{
Dr. Luis I. Gordillo PÉreZ² \\ Profesor de Derecho Constitucional \\ Universidad de Deusto (Bilbao, España) \\ gordillo@deusto.es
}

RESUMEN. El presente artículo analiza actividad sancionadora del Consejo de Seguridad de las Naciones Unidas desde la perspectiva constitucional. Tras constatar las dificultades iniciales para exigir responsabilidad a las organizaciones internacionales en general, el trabajo se centra en las llamadas sanciones "inteligentes", directas o selectivas y en las vías para limitar este poder sancionador del Consejo de Seguridad. El autor concluirá que es necesario que dicho organismo vaya asumiendo progresivamente los principios constitucionales que otros ordenamientos de naturaleza constitucional manejan para garantizar la legitimidad de su poder sancionador, la efectividad de dichas sanciones así como contribuir a la progresiva estabilización de las relaciones interordinamentales.

ABSTRACT. This article analyzes the sanctioning power of the UN Security Council from a constitutional perspective. After acknowledging the difficulties of the International Organizations to be accountable, this paper focuses on the so-called "smart" or "targeted sanctions" and the ways to limit the sanctioning power of the Security Council. The author will conclude on the necessity for this organism to assume progressively certain constitutional principles that other constitutional legal orders accept in order to guarantee the legitimacy of its sanctioning power, the effectiveness of these sanctions as well as to contribute to the stabilization of the inter-ordinal relations.

PALABRAS CLAVE. Consejo de Seguridad de la ONU, Sanciones inteligentes, ordenamientos constitucionales, derechos fundamentales.

KEYWORDS. UN Security Council, Smart/targeted sanctions, constitutional legal orders, human rights.

\footnotetext{
${ }^{1}$ Artículo recibido el 10 de mayo de 2011 y aprobado el 1 de febrero de 2012.

2 Doctor (con mención europea) por la Universidad de Deusto (2010), visiting scholar Benjamin Cardozo School of Law (Nueva York, 2008) y Secretario de la revista jurídica Estudios de Deusto (ISSN: 0423-4847). Entre sus últimas obras, destaca La naturaleza del Estado. Origen, tipología y lógica de actuación política y social (con Ignacio Ma Beobide) Tecnos, Madrid, 2012 o Interlocking Constitutions. Towards an Interordinal Theory of National, European and UN Law, Hart, Oxford, 2012. Premio Nicolás Pérez-Serrano (2009-2010) a la mejor tesis doctoral del Centro de Estudios Políticos y Constitucionales (Madrid, España).
} 


\section{INTRODUCCIÓN}

1. Existe un número cada vez mayor de organizaciones internacionales, desde las inspiradas en filosofías funcionalistas o regionales creadas para hacer frente a necesidades transnacionales específicas o para lograr objetivos concretos, hasta las grandes organizaciones multilaterales creadas para hacer frente a tareas comunes más generales o fundamentales (políticas, económicas, culturales, militares, técnicas, etc.), todas ellas con muchas variaciones ${ }^{3}$. De hecho, dada la diversidad de perfiles que presentan, la doctrina internacionalista ha encontrado dificultades a la hora de construir una teoría general e incluso una definición concreta de la organización internacional ${ }^{4}$. Así, en sentido tradicional, se entiende por organización internacional "una unión de varios sujetos de Derecho internacional, constituida sobre base paritaria, dotada de un ordenamiento propio y de órganos e instituciones propias, orientada a conseguir, conforme a su acto institutivo, una finalidad común a los miembros que la componen"s. Por tanto, en principio, las organizaciones internacionales no serían instituciones políticas superiores, sino que se asientan en el principio de cooperación y de respeto a la soberanía estatal. No obstante, entre la doctrina fue abriéndose paso un nuevo tipo de organización: las organizaciones supranacionales o de integración, que se apartarían de los anteriores postulados ${ }^{6}$. Este tipo de organizaciones trascenderían el imperativo de cooperación a que responde toda organización internacional para "plasmar la alienación de ciertas competencias soberanas en la búsqueda de una unidad superior en cuyo interior las fronteras se hacen más flexibles y permeables" . En contraposición con las características de las organizaciones de cooperación, las de integración se distinguirían por la cesión de competencias soberanas realizada por los Estados integrantes, en principio en materias concretas, en su favor, que son ejercidas por medio de órganos legitimados para actuar directamente sobre los ciudadanos ${ }^{8}$. Estas organizaciones, además, recortarían o limitarían la soberanía de sus Estados miembros, pues nacen con la intención de crear una entidad con poderes propios para la consecución de objetivos comunes, generalmente económicos o políticos?.

\footnotetext{
${ }^{3}$ Pastor Ridruejo (2010), pp. 657-667.

${ }^{4}$ Sobre esta cuestión vide, en general, SCHERMERs (1991), pp. 69-105.

${ }^{5}$ Monaco (1965), p. 12.

${ }^{6}$ Colliard y Dubois (1995), p. 171.

7 Pérez Vera (1977), p. 670.

${ }^{8}$ Braillard y Djalili (1992), p. 113.

${ }^{9}$ La literatura sobre este punto es muy abundante. Para una panorámica general, vide SCHERMERS y BLOKKER (2004), especialmente, pp. 21-39. Para un análisis politológico de la Unión Europea y, más ampliamente, del fenómeno de la integración europea, vide MarisCAL (2003) y Gordillo (2005).
} 
2. Junto a estos desarrollos en el plano institucional, existe abundante literatura y gran interés doctrinal por lo que se ha dado en llamar el "pluralismo jurídico" y la no menos estudiada "fragmentación internacional" (o "fragmentación del Derecho internacional"), ambos derivados del aumento de la densidad del entorno jurídico internacional ${ }^{10}$. De este modo, mientras que antes el debate se centraba en los ordenamientos locales e infraestatales que coexistían en un mismo ámbito espaciotemporal de carácter nacional, ahora el interés se dirige hacia lo supraestatal, hacia los ordenamientos jurídicos globales que coexisten en el mundo junto con los preexistentes sistemas estatales e infraestatales ${ }^{11}$.

3. Dada la inexistencia de un sistema jurídico internacional ordenado que defina competencias y asigne jurisdicciones, la relación entre estos distintos tipos de entidades entre sí, así como las relaciones entre los Estados, las organizaciones internacionales y otros actores internacionales resultan complicadas y algunos de los problemas que se generan siguen sin tener una solución final. Existen significativos solapamientos entre la jurisdicción que estos distintos sujetos pretenden ejercer, y sus poderes y competencias normalmente no están definidos ni concretados de un modo tal que se eviten los conflictos con los otros y ni siquiera se establece la forma en la que tales conflictos deberían ser abordados ${ }^{12}$. Esta situación puede ser entendida desde dos concepciones distintas. Por una parte, el interés en estos solapamientos y las demás complicaciones derivadas de la cada vez mayor fragmentación del ordenamiento jurídico internacional respondería a una visión formalista, derivada del deseo kelseniano de establecer un ordenamiento jurídico global perfectamente jerarquizado como resultado de la transposición de los principios reguladores del ordenamiento jurídico estatal al ámbito internacional ${ }^{13}$. Otro punto de vista, sin embargo, defendería que en la situación descrita habría un interés superior al mero deseo de establecer unos principios ordenadores concretos

\footnotetext{
${ }^{10}$ Entre la abundante doctrina sobre el "pluralismo jurídico", vide Berman (2007a), Berman (2007b), KRISCH (2006), Walker (2002), Halberstam (2011), Tamanaha (2008), Koskenniemi y Leino (2002), Teubner y Fischer-Lescano (2004), Buffard et al. (2008) y Gordillo (2012). La "Comisión de Derecho Internacional" (International Law Commission o "ILC") estableció en 2002 un grupo de estudio sobre este tema con el nombre de "Fragmentation of International Law: Difficulties arising from the Diversification and Expansion of International Law". Dicho grupo presentó un informe a la Asamblea General de Naciones Unidas en 2006 (U.N. Doc.A/ CN.4/L.702, de 18 julio 2006, ref. GE.06-62863 [E] 200706). Para más información sobre este grupo y su trabajo, puede consultarse su página web <http://untreaty.un.org/ilc/guide/1_9.htm>, última consulta: 14 enero 2011.

${ }^{11}$ Sousa-Santos (2003), p. 92.

${ }^{12}$ Para un resumen de los técnicas que el Derecho internacional en general y la Convención de Viena sobre Derecho de los Tratados en particular prevén para resolver estos conflictos, vide el Informe de la Comisión de Derecho Internacional, U.N. Doc. A/CN.4/L.702 (2006), especialmente, $\$ 14$ en el que sintetiza sus conclusiones.

${ }^{13}$ En este sentido, vide el clásico Kelsen (1965), especialmente, pp. 343-383. Más recientemente, vide KenNedy (2007).
} 
o la defensa de la esperanzas de hegemonía del liberalismo jurídico internacional ${ }^{14}$. Muchas de estas organizaciones internacionales han estado expandiendo sus competencias desde su creación misma, ejerciendo cada vez en mayor medida funciones propias de un gobierno y aumentando su autonomía y su autoridad y, al mismo tiempo, generalmente muestran dos tendencias complementarias. Por una parte, tienden a concentrar y reforzar sus competencias ejecutivas y administrativas. Para hacer esto, otorgan competencias a las instancias ejecutivas nacionales que pretendidamente representan los intereses estatales en el foro internacional y a las nuevas estructuras burocráticas que integran las secretarías y los entramados institucionales de estas organizaciones ${ }^{15}$. En segundo lugar, dichas organizaciones tienden a no proporcionar mecanismos ni para exigir su responsabilidad ni para controlar su actividad, características que, sin embargo, sí aparecen en el ámbito estatal. Así pues, este modelo de gobierno internacional resulta particularmente alejado del ciudadano y genera importantes problemas de exigencia de responsabilidad en el cada vez más complejo escenario transnacional, de legitimidad de la propia organización, sin olvidar la posible vulneración por parte de estas entidades de derechos fundamentales reconocidos en textos de naturaleza constitucional ${ }^{16}$.

4. El objetivo de este trabajo consiste en analizar el poder sancionador del Consejo de Seguridad de las Naciones Unidas desde la perspectiva constitucional, señalando las prácticas actuales, los cambios introducidos y la necesidad de nuevos avances en la materia. Tras constatar las dificultades iniciales para exigir responsabilidad a las organizaciones internacionales, en general, el trabajo se centra en las llamadas sanciones "inteligentes", directas o selectivas y en las vías para limitar este poder sancionador del Consejo de Seguridad. Finalmente, se concluirá que es necesario que dicho organismo vaya asumiendo progresivamente los principios constitucionales que otros ordenamientos de naturaleza constitucional manejan para garantizar la legitimidad de su poder sancionador, la efectividad de dichas sanciones así como contribuir a la progresiva estabilización de las relaciones interordinamentales.

\section{LA RESPONSABILIDAD A LAS ORGANIZACIONES INTERNACIONALES Y LAS DIFICULTADES DE SU EXIGENCIA.}

5. Cuando se causa un daño indebido a través de las políticas o de los actos de organizaciones internacionales, normalmente no existe una vía adecuada para que

\footnotetext{
${ }^{14}$ De BúrCa (2010), pp. 32-33.

${ }^{15}$ Scheppele (2006a) y Scheppele (2006b), pp. 347-373.

${ }^{16}$ La literatura sobre esta cuestión es abundante. Entre las principales aportaciones, vide STEPHAN (1997), Slaughter (2001), Keohane (2003), Keohane y Nye (2003), Grant y Keohane (2005), Hale (2008).
} 
los afectados puedan lograr una reparación. El borrador de normas de la Comisión de Derecho Internacional sobre "Responsabilidad de las Organizaciones Internacionales", que aún está siendo discutido, aunque algunos de sus puntos ya han sido adoptados provisionalmente, se basa en el trabajo homólogo de la Comisión dedicado a la responsabilidad de los Estados (Draft Articles on State Responsibility) con la particularidad de que el beneficiario de la reparación sería el Estado y no el individuo ${ }^{17}$. Incluso cuando los tribunales nacionales se muestran receptivos en principio para conocer de acciones contra organizaciones internacionales, existen normalmente normas sobre inmunidad y otras barreras de tipo procesal que limitan, cuando no anulan, la posibilidad de responsabilizar jurídicamente a estas organizaciones por sus acciones ${ }^{18}$.

6. Una posible explicación a la escasez de mecanismos jurídicos de exigencia de responsabilidad de las organizaciones internacionales consistiría en sugerir que, en la práctica, no es necesario tal mecanismo en manos de los particulares, dada la estructura y la naturaleza de las organizaciones internacionales. En otras palabras, la lógica del diseño institucional de la mayoría de ellas asume que dichas organizaciones no pueden afectar a los particulares directamente. En tanto en cuanto se trata de organizaciones establecidas entre Estados, no ejercerían sus competencias directamente sobre los individuos, ni desde el punto de vista jurídico ni desde el institucional ${ }^{19}$. En su lugar, existirían agentes o intermediarios, es decir, distintos niveles de autoridad nacionales e infranacionales que implementarían y aplicarían

${ }^{17}$ El trabajo de la Comisión de Derecho Internacional titulado Proyecto de artículos sobre la responsabilidad del Estado por hechos internacionalmente ilícitos fue incluido en la resolución de la Asamblea General de Naciones Unidas de 12 diciembre 2001 en su 85a sesión (A/RES/56/83) como anexo titulado Responsabilidad del Estado por hechos internacionalmente ilicitos (Responsibility of States for Internationally Wrongful Acts). Sobre esta cuestión, vide CRAWFORD (2002), especialmente pp. 1-60, donde se realiza una interesante introducción sobre la cuestión. Vide también la versión en castellano CraWFORD (2005).

${ }^{18}$ ReINISCH (2000), especialmente, pp. 317-390 y ReINISCH (2001), especialmente, pp. 866-867, donde se refiere a la posibilidad de demandar a la ONU ante los tribunales nacionales. Igualmente, vide SINGER (1995), WelLens (2002) y WelLens (2004). Sobre la problemática de la responsabilidad de las organizaciones internacionales en relación con las sanciones de Naciones Unidas, vide BotHe (2008) y REICH (2010).

${ }^{19}$ Una importantísima excepción la constituirían las antiguas Comunidades Europeas (hoy UE), cuyos tratados fundacionales les garantizaban competencias que implicaban la eficacia directa de sus decisiones sobre los individuos, lo que se acompañó, también desde un primer momento, con ciertas limitaciones y posibilidades de exigencia de responsabilidad ante el Tribunal de Justicia. Recientemente, incluso un grupo de jueces del TEDH se ha llegado a cuestionar que los mecanismos de exigencia de responsabilidad en manos de los particulares en el ámbito comunitario sean suficientes. Sobre esta cuestión, vide los votos particulares de los jueces Rozakis, Tulkens, Traja, Botoucharova, Zagrebelsky y Garlicki, y el del juez Ress, en el caso Bosphorus vs. Irlanda (TEDH, 2005). Sobre este caso, vide, v. gr., Douglas-SCOTT (2006) y Gordillo (2011), donde se analizan las consecuencias de la próxima adhesión de la UE al Convenio Europeo de Derechos Humanos. 
las normas o políticas establecidas en el ámbito intergubernamental, y serían en estos niveles nacionales e infranacionales donde se deberían ejercer los mecanismos de exigencia de responsabilidad. Desde este punto de vista, no debería causar revuelo alguno el que la ONU o, incluso, la Unión Europea, cuando actúa como una organización intergubernamental en el ámbito del segundo pilar (Política Exterior y de Seguridad Común), tuvieran que responder por los daños causados a particulares por actos emanados originalmente de sus órganos. Mientras que los Estados puedan responder unos frente a otros en el seno de las organizaciones internacionales, y los órganos ejecutivos que representan a los Estados dentro de esas organizaciones tengan que rendir cuentas ante sus gobiernos y parlamentos, $o$ se pueda exigir la responsabilidad de los funcionarios incardinados en las estructuras burocráticas de la organización ante otras instituciones de dicha organización, no sería necesaria la creación de un marco legal que disponga la responsabilidad directa de esas organizaciones frente a quien en última instancia resulta afectado por las acciones de éstas ${ }^{20}$.

Sin embargo, esta argumentación simplificaría demasiado la cuestión y resultaría poco fundada. Esta caracterización tradicional de la esfera de influencia y del impacto de las organizaciones internacionales pasaría por alto la forma en la que éstas han evolucionado y el hecho de que muchas de esas organizaciones han ido adquiriendo progresivamente importantes competencias administrativas e, incluso, normativas. Incluso si el eventual impacto de sus actos estaría condicionado a través de una cadena de actos y normas intermedias, lo habitual es que dichos actos intermedios no son tampoco recurribles porque se consideran que las autoridades nacionales, en su caso, estarían obligadas a implementar las normas de la organización supranacional, y el tribunal que pudiera entender del caso se mostrará reticente a controlar directamente dichas medidas por temor, entre otras cosas, a hacer incurrir al Estado afectado en responsabilidad internacional. Así, la responsabilidad última derivada del acto de la organización recaería en la organización en sí misma. Un ejemplo de esta situación sería el protagonizado por el Consejo de Seguridad de Naciones Unidas. Dicho órgano de la ONU ha empezado a ejercer funciones de tipo legislativo al amparo del capítulo VII de la Carta cuando, por ejemplo, adopta resoluciones por las que requiere a los Estados que congelen fondos y activos de individuos sospechosos o implicados en actividades terroristas ${ }^{21}$. Igualmente, otra muestra del ejercicio de competencias legislativas serían el establecimiento del Comité contra el terrorismo y los Comités

${ }^{20}$ Vide ReInISCH (2000), pp. 233-251, que resume los argumentos de esta visión clásica.

${ }^{21}$ Fremuth y Griebel (2007), Hinojosa Martínez (2008), Cohen (2008). 
de Sanciones ${ }^{22}$. Dichas resoluciones, obviamente, requieren de la correspondiente implementación por parte de los Estados o por parte de las organizaciones regionales como, por ejemplo, la Unión Europea, para poder efectivamente (más allá de cuestiones de reputación o imagen pública) limitar los derechos de propiedad de los particulares. No obstante lo anterior, resultaría impreciso concluir que la responsabilidad primaria por los daños causados a resultas de la congelación de los fondos de personas incluidas equivocadamente en unos listados reside en el Estado que se ha limitado a ejecutar una resolución obligatoria del Consejo de Seguridad antes que en el propio Consejo de Seguridad que equivocadamente incluyó el nombre de una persona en un listado de terroristas cuyos bienes debían ser embargados. Aun en el caso de que se pudiera concluir que el Estado es legalmente responsable por el daño ocasionado, el artículo 103 de la Carta de Naciones Unidas proporcionaría al Estado en cuestión un mecanismo de defensa basado en la superior jerarquía del ordenamiento de Naciones Unidas, subordinando la protección del individuo y la eventual responsabilidad del Estado en cuestión por los daños causados a las obligaciones derivadas de la Carta que serían preeminentes y derogarían cualquier otro compromiso del Estado.

Otro ejemplo del impacto directo e, incluso, potencialmente dañino de medidas autorizadas por las Naciones Unidas se refiere a los actos de las administraciones territoriales de dicha organización. Al igual que la evolución de los poderes normativos del Consejo de Seguridad, en los últimos años se viene observando igualmente la eclosión de otra tarea propia de un gobierno por parte del mencionado órgano de la ONU, esto es, la administración de territorios en situaciones concretas de conflicto o posteriores a él ${ }^{23}$. Este tipo de administración territorial de las Naciones Unidas ha sido visto en Timor Oriental, Bosnia y Kosovo y es claro que dicho poder de administración y gobierno lleva aparejado la posibilidad de causar un daño determinado. Incluso aunque en esta situación el potencial de un daño causado directamente por las Naciones unidas es mucho más evidente, la cuestión relativa a los mecanismos de rendición de cuentas y a la responsabilidad

\footnotetext{
${ }^{22}$ Una lista actualizada de los Comités de sanciones del Consejo de Seguridad se encuentra disponible en su sitio web <http://www.un.org/spanish/docs/sc/unsc_estructura.html>, última consulta: 14 enero 2010.

${ }^{23} \mathrm{La}$ administración de territorios bajo los auspicios de la ONU no constituye una invención reciente, como lo muestra el propio capítulo XII de la Carta, titulado "Régimen Internacional De Administracion Fiduciaria”. En todo caso, sí que hay puntualizar que bajo el sistema de administración fiduciaria, los territorios que pasaban de ser colonias a constituirse en Estados independientes eran generalmente administrados transitoriamente por la antigua potencia colonial bajo la supervisión y los auspicios de la ONU, pero no por la ONU directamente como, en cambio, sí ha sucedido más recientemente en Kosovo y Timor Oriental. Sobre esta cuestión, vide WIDE (2008), especialmente, pp. 47-98.
} 
jurídica de dichas administraciones territoriales no tiene fácil respuesta ${ }^{24}$. Además, las acciones emprendidas para establecer mecanismos internos de exigencia de responsabilidad no han producido los resultados esperados ${ }^{25}$.

7. Una segunda posible explicación a la escasez de mecanismos jurídicos de exigencia de responsabilidad de las organizaciones internacionales se centraría en argumentar que la responsabilidad directa de dichas organizaciones a favor de los particulares minaría el funcionamiento de la organización. Esta tesis se basa no en el argumento de que las organizaciones son incapaces de causar un daño tal que mereciera el establecimiento de la responsabilidad, sino en el argumento que insiste en que dicha responsabilidad perjudicaría el funcionamiento de la organización ${ }^{26}$. Esta explicación de tipo funcional evidentemente varía dependiendo de los objetivos y propósitos de la organización, pero términos generales vendría a significar que la cooperación internacional es en sí misma un bien que ha de ser fomentado y protegido y que el daño colateral derivado de dicha cooperación no debe conducir a la imposición de la obligación jurídica de responder por los daños causados. Como se recordará, esta es la tesis que sustenta la argumentación del Tribunal Europeo de Derechos Humanos. En efecto, según el TEDH:

"El Tribunal [Europeo de Derechos Humanos] ha reconocido hace mucho tiempo la creciente importancia de la cooperación internacional y la consiguiente necesidad de asegurar el correcto funcionamiento de las organizaciones internacionales" 27.

En caso contrario, continuaría esta argumentación, existiría un riesgo de que la organización se inhiba ella misma demasiado, lo que impediría la consecución de determinadas políticas por temor a ser declarada responsable y tener que asumir las consecuencias. Este tipo de argumentación de tipo funcional es la que fundamenta la mayoría de las reglas de la inmunidad ${ }^{28}$. Pero este tipo de razonamiento

\footnotetext{
${ }^{24}$ Vide el Dictamen 280/2004 de la Comisión Venecia sobre los derechos humanos en Kosovo y el Informe del Secretario General de Naciones Unidas de 12 julio 1999, especialmente $\$ 85$, en el que interpretó que la Resolución 1244 sobre el establecimiento de la administración de la ONU en Kosovo obligaba a dicha administración a respetar los derechos humanos internacionalmente reconocidos en el ejercicio de su autoridad.

${ }^{25}$ Vide Knoll (2007). Vide, igualmente el Dictamen 280/2004 de la Comisión Venecia y el Informe del Comité de Derechos Humanos del Pacto Internacional sobre derechos civiles y politicos de 14 agosto 2006 sobre la Administración Interina de la Misión de Naciones Unidas en Kosovo.

${ }^{26}$ De BúrCA (2010), p. 11.

${ }^{27}$ Caso Bosphorus v. Irlanda (TEDH, 2005), $\$ 150$, cit. Sobre la cooperación en general y la cooperación internacional en el ámbito de Naciones Unidas, vide el caso Behrami vs. Francia y Saramati vs. Francia, Alemania y Noruega (TEDH, 2007), \$\$145-152. Sobre los casos Behrami y Saramati, vide Rey-Aneiros (2008) y SARI (2008).

${ }^{28}$ Vide Reinisch (2000), pp. 233-239, Lalive (1954) y, en general, Morgenstern (1986).
} 
para excluir la responsabilidad jurídica es exagerado. Mientras que es claro que la rutinaria imposición de la responsabilidad legal por cualquier daño causado representa un elemento disuasorio para una organización que persiga fines que necesariamente impliquen riesgos a los intereses y derechos de otros, una norma que prescribiera la inmunidad absoluta o la libertad frente a todo tipo de rendición de cuentas entrañaría el riesgo opuesto, es decir, garantizaría la impunidad frente a posibles arbitrariedades y abusos por parte de la organización inmune. Además, el razonamiento que esgrime que la mera existencia de la responsabilidad jurídica dificultaría el funcionamiento de la organización parece exagerado. Así, mientras que parece razonable sugerir que la imposición de un estándar de responsabilidad excesivamente alto perjudicaría el trabajo habitual de una organización internacional, existe un gran abanico de posibilidades entre esta opción y la regla de la inmunidad ${ }^{29}$. No habría, pues, razones de peso para descartar que un conjunto de principios sobre responsabilidad cuidadosamente establecidos no pueda ser capaz de establecerse en un punto intermedio entre el riesgo de prácticas defensivas derivadas de un estándar de responsabilidad demasiado alto y el riesgo de abuso derivado de la impunidad. Finalmente, otro argumento similar, aunque de naturaleza más institucional que funcional, para excluir que las autoridades nacionales o regionales puedan exigir la responsabilidad jurídica de las organizaciones internacionales defiende que ello supondría una extralimitación de las competencias jurisdiccionales de dichas autoridades ${ }^{30}$.

8. Varias caracterizaciones del entorno jurídico internacional, además, enfatizan la existencia de solapamientos, vinculaciones múltiples e intersecciones de distintos niveles de autoridad. Esto daría la impresión de que el principal problema sería cómo gestionar las variadas reclamaciones jurisdiccionales que pueden surgir, cómo enfrentarse con el conflicto potencial de la autoridad competente y cómo fomentar el diálogo y la cortesía mutua pasando de un escenario de exigencia de responsabilidad a otro más apropiado a través de los principios de deferencia o complementariedad ${ }^{31}$. Sin embargo, el problema puede consistir también en que la proliferación de organizaciones e instituciones internacionales, más que multiplicar las instancias potenciales y los mecanismos de rendición de cuentas y de

\footnotetext{
${ }^{29}$ Keohane y Nye (2003) así como Grant y Keohane (2005).

${ }^{30}$ Un argumento de esta naturaleza que intentó hacer valer el Reino Unido en el caso Kadi sería totalmente descartado por el Abogado General, Sr. PoiAres Maduro. Vide las Conclusiones del Abogado General en los asuntos acumulados Kadi/Al Barakaat v. Consejo (TJCE, 2008).

${ }^{31}$ Berman (2007b). En definitiva, no se trataría más que de recuperar los principios clásicos de las relaciones entre naciones de los estatutarios holandeses, la clásica comitas gentium. Sobre esta cuestión, vide MeIJERS (1970).
} 
control jurisdiccional, de hecho dejan un vacío de responsabilidad legal allí donde la organización internacional no prevé ningún tipo de mecanismo de control, y los poderes públicos nacionales o intermedios consideran que tampoco ellos son responsables por los actos en cuestión y que no tienen jurisdicción para cuestionar la responsabilidad de otra autoridad nacional o internacional ${ }^{32}$.

9. Fueron precisamente estos dilemas relativos a la rendición de cuentas y a la responsabilidad internacional los que emergieron en los casos Kadi/Al Barakaat ante el TJUE (entonces, TJCE) y Behrami/Saramati ante el TEDH, donde el complejo carácter de las organizaciones internacionales en cuestión agudizaron el dilema de la responsabilidad que se suscitó en los citados tribunales regionales europeos $^{33}$. En lo que al Consejo de Seguridad de Naciones Unidas se refiere, no sólo ha expandido éste su papel y sus poderes más allá de lo que originalmente se preveía en la Carta para incluir un tipo de medidas legislativas que emplea en el contexto de la lucha contra el terrorismo o los significativos poderes de gobierno que ejerce en Kosovo y otros lugares, sino que su anómala y compleja composición, las profundas divisiones ideológicas y las luchas políticas que han lastrado su funcionamiento también han debilitado su legitimidad como el principal órgano de gobierno responsable de la paz y la seguridad ${ }^{34}$. No obstante, si la ONU en general y su Consejo de Seguridad en particular sufren de un particular déficit de legitimidad, la situación de la Unión Europea, aunque sustancialmente mejor, tampoco es idílica. Así, mientras que desde un punto de vista la UE es el ejemplo contemporáneo de mayor éxito en lo que a la integración regional se refiere, habiendo construido una robusta unión económica pasando de los seis miembros iniciales a los veintisiete de la actualidad (con candidatos esperando su ingreso), desde otra perspectiva está dividida internamente y externamente constituye un débil actor sobre la escena internacional cuyo último fracaso consiste en no haber sido capaz de dotarse de una constitución (y ni siquiera un tratado que optimice su funcionamiento), lo que ha dinamitado el ya viejo deseo de mejorar su legitimidad política y democrática ${ }^{35}$.

\footnotetext{
${ }^{32}$ Sobre esta cuestión, en la doctrina norteamericana existe un concepto que gustó mucho a los comentaristas, la llamada "redundancia jurisdiccional". Vide COVER (1981). Sobre cómo la adhesión de la UE coadyuvará a la estabilización de las relaciones entre el ordenamiento de la UE y el sistema del CEDH, vide Gordillo (2011).

${ }^{33}$ Asuntos acumulados Kadi/Al Barakaat v. Consejo (TJCE, 2008) y casos Behrami v. Francia y Saramati v. Francia, Alemania y Noruega (TEDH, 2007).

${ }^{34}$ Para un análisis crítico sobre la problemática de la rendición de cuentas del Consejo de Seguridad, vide KOSKENNIEMI (1995).

${ }^{35}$ Sobre esta cuestión, la literatura es abundante. Para una muestra, vide Odvar y Fossum (2004), Hansen
} 


\section{El POder SANCIONADOR del CONSEJO DE SEgURIDAD DE LA ONU}

\subsection{Las llamadas sanciones directas, selectivas o "inteligentes"}

10. De acuerdo con el artículo 24.1 de la Carta de Naciones Unidas, el Consejo de Seguridad tiene la responsabilidad primordial de mantener la paz y la seguridad internacionales ${ }^{36}$. Así, tras determinar, según lo dispuesto en el artículo 39, que una situación constituye una amenaza o un quebrantamiento de la paz, el Consejo de Seguridad puede instar a los Estados a adoptar medidas provisionales (artículo 40), medidas que no impliquen el uso de la fuerza, a las que normalmente se las llama sanciones (artículo 41) y, finalmente, acciones militares contra los responsables de la amenaza o del quebrantamiento (artículo 42) ${ }^{37}$. El Consejo de Seguridad rara vez establece explícitamente qué artículo constituye la base legal de sus resoluciones, sino que se limita a constatar que actúa "con arreglo al Capítulo VII de la Carta" 38 . La tipología de medidas que no implican el uso de la fuerza armada varía considerablemente, pero es posible distinguir entre embargos económicos y comerciales dirigidos directa y expresamente contra una entidad en particular y un abanico de medidas menos directas. No existe una definición generalmente aceptada de estas sanciones "directas" (targeted, en inglés) o "selectivas" (ciblées, en francés) que impone el Consejo de Seguridad, sin embargo, se entiende que el concepto abarca la congelación de depósitos financieros, la suspensión de créditos y ayudas económicas, la denegación y limitación del acceso a mercados financieros extranjeros, embargos comerciales sobre armas y bienes de lujo, prohibiciones de vuelos y denegación de desplazamientos internacionales, visados y realización de estudios en el extranjero ${ }^{39}$. A estas sanciones "directas" o "selectivas" se las llama

y Williams (2002) y Horeth (1999).

${ }^{36}$ Sobre la teoría de las sanciones, vide ABI-SAAB (2001).

37 Vide Österdahl (1998) y Frowein y Krisch (2002), especialmente, pp. 701-763.

${ }^{38}$ Vide, por ejemplo, la Resolución № 1.160 (1998), de 31 marzo, S/RES/1160 (1998). Para un análisis reciente de los poderes que ejerce el Consejo de Seguridad, especialmente en la lucha contra el terrorismo, vide Denis (2004), especialmente, pp. 133-161, Hilaire (2005), especialmente, pp. 253-290 y FarRalL (2007), especialmente, pp. 79-181.

${ }^{39}$ Algunos ejemplos aparecen en el Informe del Secretario General de las Naciones Unidas sobre la Protección de los Civiles en los Conflictos Armados, de 8 septiembre 1999, \$54 y en el BossuYT report (The Adverse Consequences of Economic Sanctions on the Enjoyment of Human Rights. Review of Further Developments in Fields with Which the Subcommission Has Been or May Be Concerned) presentado por el autor ante el Consejo Económico y Social de la ONU, 21 junio 2000, \$11-17. Sobre estas sanciones, en general, vide GowLLanDDebbas (2001), Picchio-Forlati y Sicilianos (2004). 
también "inteligentes" (smart, en inglés), haciendo un macabro paralelismo con las "bombas inteligentes" (smart bombs, que están destinadas a objetivos específicos) ${ }^{40}$. No todos los regímenes sancionadores del Consejo de Seguridad implican sancionar a personas concretas. Los principales sistemas sancionadores que sí lo hacen son los relativos a Angola, Liberia, Sierra Leona y Afganistán. Así, cuando las sanciones están dirigidas contra individuos, éstas se ejecutan a través de las llamadas "listas negras" (blacklists, en inglés). El Consejo de Seguridad adopta una resolución y delega en un comité de sanciones, integrado por todos los miembros del propio Consejo de Seguridad, la tarea de concretar la lista de las personas afectadas por el régimen sancionador ${ }^{41}$.

\subsection{Las sanciones directas y los derechos de los sancionados}

11. La cuestión de las sanciones "inteligentes" ha suscitado el interés de la doctrina, especialmente en lo que a su control se refiere. Existe una vasta literatura sobre la materia, concretamente, sobre el papel de la Secretaría de la ONU en la coordinación, seguimiento y control de la efectividad de las medidas, pero no existe una opinión unánime sobre la eficacia de estas sanciones ${ }^{42}$. Las sanciones "inteligentes" han sido objeto de estudio y discusión, además, en numerosos foros diplomáticos, académicos y en conferencias auspiciadas por organizaciones no gubernamentales, entre ellos, el proceso de Interlaken, el de Bonn-Berlín y el de Estocolmo, donde se discutieron los sistemas de implementación de estas sanciones y, especialmente, las propuestas de mejora ${ }^{43}$. Las sanciones económicas generales afectan a la vida de un mayor número de personas que las sanciones selectivas que, sin embargo, tienen un destinatario claro. Sin embargo, la cuestión de si ciertas garantías legales, incluyendo las relativas a los derechos humanos, deberían o no aplicarse a las sanciones "inteligentes" de las Naciones Unidas

${ }^{40}$ Cortright y López (2000), p. 240.

${ }^{41}$ La lista actualizada de los Comités de sanciones del Consejo de Seguridad se encuentra disponible en su sitio web <http://www.un.org/spanish/sc/committees/composition.shtml>, última consulta: 14 enero 2011.

${ }^{42}$ Entre otros estudios críticos, vide DoXey (1996), Pape (1997), Pape (1998), Elliott (1998), Baldwin (1999), Cortright y Lopez (2002) así como Wallensteen y Staibano (2005).

${ }^{43}$ Todos esos foros produjeron sendos informes finales. Así, vide Biersteker, T. (2001): Targeted Financial Sanctions. A Manual for Design and Implementation. Contribution from the Interlaken Process (Providence, Brown University, 2001), Brzoska, M. (2002): Design and Implementation of Arms Embargoes and Travel and Aviation Related Sanctions: Results of the "Bonn-Berlin Process", International Center for Conversion (Bonn) y Wallensteen, P., Staibano, C. (2003): Making targeted sanctions effective: guidelines for the implementation of UN policy options (Stockholm, Elanders Gotab). 
sólo se ha planteado hace relativamente poco tiempo ${ }^{44}$. Por lo demás, el Consejo de Seguridad no es la única instancia que aplica regímenes sancionadores. Además de la actividad sancionadora de la Unión Europea (casos PMOI-OMPI), Estados Unidos, por ejemplo, ha establecido distintos regímenes sancionadores unilaterales y, entre otras, viene empleando la técnica de las "listas negras" desde hace algo más tiempo que el propio Consejo de Seguridad ${ }^{45}$. Estos regímenes sancionadores unilaterales (Estados Unidos) y regionales (Unión Europea) pueden ser problemáticos desde el punto de vista de las garantías legales y, así, compartirían características con el sistema propio de Naciones Unidas ${ }^{46}$.

12. El Consejo de Seguridad comenzó a emplear las sanciones directas (targeted, en inglés) con el régimen sancionador que estableció contra la organización Unión Nacional para la Independencia Total de Angola (UNITA) en 1997 y $1998^{47}$. La última lista negra relativa a Sierra Leona contaba con una treintena de personas a las que se prohíbe viajar ${ }^{48}$. En cuanto a Liberia, las prohibiciones de viajar llegaron a afectar a 47 personas $^{49}$. El régimen sancionador relativo a Sierra Leona y Liberia ha dado lugar a quejas y discusiones en los correspondientes comités sancionadores relativas a las razones para añadir nombres a las listas negras ${ }^{50}$. No obstante, dado que el objetivo de estas sanciones era penalizar a líderes gubernamentales y rebel-

\footnotetext{
${ }^{44}$ Vide, por ejemplo, el informe que el profesor Cameron escribió para el Gobierno sueco en el momento en que éste albergaba el ya mencionado "proceso de Estocolmo", Cameron, I. (2002): Report to the Swedish Foreign Office on Legal Safeguards and Targeted Sanctions (Stockholm, SPITS). Las conclusiones principales de este informe también aparecen en Cameron (2003). Igualmente, del mismo autor, vide el informe realizado para el Consejo de Europa, Cameron, I. (2006): The European Convention on Human Rights, Due Process and United Nations Security Council Counter-Terrorism Sanctions (Strasbourg, Council of Europe, 6 febrero).

45 Vide, entre otros, Fitzgerald (1999), Fitzgerald (2002) y Eckes (2007).

${ }^{46}$ Para una panorámica general de los problemas que plantea el régimen sancionador autónomo y el que implementa el propio de Naciones Unidas, vide BrandTNER y Rosas (1998), CANOR (1998), ANDERSSON et al. (2003).

${ }^{47}$ La resolución 1127 (1997) impuso restricciones a los desplazamientos de los líderes de UNITA y sus familiares directos, S/RES/1127(1997), de 28 de agosto. Las resoluciones 1173 (1998) -S/RES/1173(1998) de 12 junio- y 1176 (1998) -S/RES/1176(1998) de 24 junio- impusieron sanciones financieras a los miembros de UNITA.

${ }^{48}$ Vide el comunicado de Prensa del Consejo de Seguridad SC/8192, de 20 septiembre 2004.

${ }^{49}$ La lista de individuos sujetos a las medidas impuestas por el párrafo 4 de la Resolución No 1.521 (2003) relativa a Liberia, que implica prohibición de viajar, se actualizó por última vez el 16 de diciembre de 2009. La lista está disponible en la web del Comité sancionador establecido en virtud de la Resolución № 1.521 (2003), <http://www.un.org/sc/committees/1521/1521_list.htm>, última consulta: 14 enero 2010.

${ }^{50}$ Vide la contestación dada por el Comité de sanciones de Liberia a las preguntas planteadas por Gambia y Líbano, S/AC.39/2002/Note. 8 y el Informe Anual del Comité de Sanciones de Sierra Leona, S/2002/470, p. 35, ambos citados por en CAMERON (2003), p. 163, nota 17.
} 
des, las discusiones se centraron en cómo identificar fehacientemente el círculo gobierno/rebeldes y qué relaciones o vínculos con esos círculos podían justificar la inclusión en los listados.

13. Los casos anteriores ilustran los problemas que plantean el proceso sancionador en relación con los derechos de los afectados. La información para incluir a los sancionados en las listas negras viene de los gobiernos a través de sus servicios de inteligencia y otras fuentes cuya identidad rara vez se airea. Los procesos de confección de listas negras son más bien oscuros, cuando no secretos y los flujos de información, perfectamente controlados por parte de los Gobiernos, tienen una naturaleza bilateral, más que multilateral. Esto es, no se presentan pruebas públicamente, sino tan solo en casos muy puntuales cuando algún Estado se muestra especialmente interesado o insistente. Los particulares afectados se encuentran en una situación especialmente vulnerable, ya que son objeto de sanciones directas pero para contestarlas tienen que recurrir a sus respectivos gobiernos o a los de sus países de residencia para que intercedan por ellos ante el Consejo de Seguridad ${ }^{51}$. En este contexto, se produce una tensión clara entre estas sanciones, o el proceso mediante el cual se establecen, y los estándares de protección nacionales e internacionales de los derechos fundamentales. De este modo, sería posible argumentar que el Consejo de Seguridad estaría limitado por las disposiciones de la Carta de Naciones Unidas en particular y por el Derecho internacional en general.

\subsection{Los límites derivados de la Carta constitucional de la ONU.}

14. La más importante fuente de obligaciones del Consejo de Seguridad deriva de la propia Carta de Naciones Unidas. El Preámbulo de la Carta narra el especial compromiso de sus signatarios con "reafirmar la fe en los derechos fundamentales del hombre, en la dignidad y el valor de la persona humana" y con "crear condiciones bajo las cuales puedan mantenerse la justicia”. Estas obligaciones generales que se reconocen a los signatarios son luego concretadas a lo largo del articulado de la Carta en propósitos, principios y disposiciones que regulan tanto la propia ONU como la conducta que deben observar sus miembros. El artículo 1 señala que entre los propósitos de las Naciones Unidas se encuentra "el desarrollo y estímulo del respeto a los derechos humanos y a las libertades fundamentales de todos, sin hacer distinción por motivos de raza, sexo, idioma o religión”. Así, según esta misma disposición, también cuando se trate de "tomar medidas colectivas eficaces para prevenir y eliminar amenazas a la paz, y para suprimir actos de agresión u otros quebrantamientos de la paz" habrá que actuar "de conformidad con

${ }^{51}$ Cameron (2003), pp. 165-166. 
los principios de la justicia y del derecho internacional". El artículo 2 establece a continuación siete principios generales destinados a orientar el funcionamiento de la organización y de sus miembros, entre los que se encuentran cumplir "de buena fe las obligaciones contraídas por ellos de conformidad con esta Carta” y de prestar a la ONU "toda clase de ayuda en cualquier acción que ejerza de conformidad

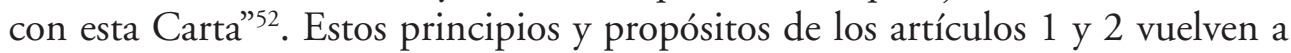
concretarse posteriormente en otras obligaciones específicas de los miembros y de la propia Organización (v.gr. en los artículos 55, 56, 24.2 y 25).

15. En todo caso, el Consejo de Seguridad posee una capacidad de acción considerable cuando actúa al amparo del capítulo VII de la Carta, lo que le puede llevar a comprometer ciertos derechos o intereses protegidos en general por el Derecho internacional. Así, cuando interviene para detener hostilidades que ya han comenzado, el Consejo de Seguridad no necesita tomar en consideración los principios generales de Derecho internacional relativos al respeto de las posiciones jurídicas de las partes beligerantes ${ }^{53}$. De la misma forma, de acuerdo con el artículo 2.7 de la Carta, la prohibición que pesa sobre las Naciones Unidas de "intervenir en los asuntos que son esencialmente de la jurisdicción interna de los Estados", que, además, es un consolidado principio general del Derecho internacional, "no se opone a la aplicación de las medidas coercitivas" que el Consejo de Seguridad podrá establecer al amparo del capítulo VII. Además, cuando actúa de acuerdo con los propósitos y principios de la Carta, el Consejo de Seguridad posee una discrecionalidad considerable, dado que dichos propósitos y principios tienden a "establecer directrices más que límites concretos a la actuación del Consejo" 54 . A pesar del amplio margen de maniobra del que goza el Consejo de Seguridad, tanto la letra como el espíritu de la Carta indicarían una obligación por parte de la ONU en general y del Consejo de Seguridad en particular de sujetar su actuación a los límites constitucionales que establece la propia Carta, lo que además incluiría el respeto general a los derechos humanos reconocidos por el Derecho internacional ${ }^{55}$. Consecuentemente, las disposiciones de la Carta impondrían a los Estados miembros la obligación de cooperar con la ONU únicamente en tanto en cuanto dicha organización ajuste su actuación a los límites que su texto fundacional le impone, incluido el respeto a los derechos humanos. Los princi-

\footnotetext{
52 Vide Schrijver (1999), Wolfrum (2002), Randelzhofer (2002) así como Müller y Kolb (2002).

${ }^{53}$ Vide Wolfrum (2002) pp. 40-43, quien añade que esta situación le da al Consejo un mayor margen de maniobra, especialmente en los momentos iniciales del conflicto.

${ }^{54}$ FroweIn y KrISCH (2002), p. 710.

${ }^{55}$ Sobre el carácter constitucional de la Carta, vide De WeT (2004), especialmente, pp. 92-116.
} 
pios y propósitos de la Carta, incluyendo la adhesión a los derechos humanos, son generales y consecuentemente redactados en un lenguaje poco concreto. Pero esta característica no hace sino reflejar la situación del estado de desarrollo de los derechos humanos en el plano internacional en el momento de la adopción de la Carta. Este instrumento jurídico, pensado como un punto de partida hacia el establecimiento y la consolidación de unos regímenes jurídicos internacionales cada vez más sólidos, lo que incluye la protección de los derechos humanos, debe ser interpretado a la luz de los avances que se vayan produciendo en la protección de los derechos humanos ${ }^{56}$.

16. Argumentos a favor de esta tesis pueden encontrarse en la doctrina y la jurisprudencia internacionales que interpretan los conceptos jurídicos establecidos en la Carta, como los principios y propósitos, a la luz del moderno Derecho internacional de los derechos humanos, la mayoría de cuyos instrumentos jurídicos ha sido patrocinada por la propia ONU. Así, hay quien defiende la vinculación de las Naciones Unidas, además de a la Declaración de los Derechos Humanos, al Pacto Internacional sobre derechos civiles y políticos y al Pacto Internacional sobre derechos económicos, sociales y culturales dado que, aunque la ONU no sea miembro de estos Tratados a través de una ratificación, dichos instrumentos representan la concreción posterior de la visión que los derechos humanos se encontraba en los propósitos originales de la Carta ${ }^{57}$. Por su parte, la Corte Internacional de Justicia ha establecido que la discriminación racial constituye "una violación flagrante de los propósitos y principios de la Carta"58. Dicho Tribunal también ha concluido también que "el hecho de privar abusivamente de la libertad a seres humanos y someterles en condiciones penosas a coacción física, es manifiestamente incompatible con los principios de la Carta de las Naciones Unidas y con los derechos fundamentales enunciados en la Declaración Universal de Derechos Humanos" ${ }^{\prime \prime}$.

Esto significaría que incluso aunque hubiera algo de cierto en la idea de que según la Carta "la paz está por encima de la justicia", las medidas dictadas al amparo del capítulo VII no pueden obviar jurídicamente las preocupaciones e intereses recogidos en los instrumentos jurídicos básicos relativos a los derechos

\footnotetext{
${ }^{56}$ Halberstam y Stein (2009), p. 18.

${ }^{57}$ Vide, entre otros, De Wet (2001), especialmente, p. 284.

${ }^{58}$ Caso relativo a las consecuencias jurídicas que tiene para los Estados la continuación de la presencia de Sudáfrica en Namibia - Africa Sudoccidental (CIJ, 1971), \$131.

${ }^{59}$ Caso relativo al personal diplomático y consular de los Estados Unidos en Teherán (CIJ, 1980), especialmente, p. $42, \$ 91$.
} 
humanos y al derecho humanitario ${ }^{60}$. Las normas sobre derechos humanos y el Derecho humanitario, más que establecer límites precisos a los poderes que ejerce el Consejo de Seguridad al amparo del capítulo VII, constituirían directrices en el ejercicio de dichos poderes. Es decir, un total desconocimiento de dichas normas, dado que forman parte de los propósitos de la Organización, según el artículo 1.3, implicaría una violación directa de la Carta. En todo caso, corresponde al Consejo de Seguridad establecer el equilibrio, en cada caso, entre los derechos humanos y el Derecho humanitario, por una parte, y el objetivo fundamental de mantener la $\mathrm{paz}^{61}$. Por lo demás, las normas internacionales sobre derechos humanos reconocen ellas mismas esta obligación de mantener un equilibrio entre paz y derechos humanos ${ }^{62}$.

17 Los Tribunales internacionales parecen confirmar este punto de vista. La Corte Internacional de Justicia reconoció hace unos treinta años que el Consejo de Seguridad estaba vinculado por los propósitos y principios de los artículos 1 y 2 de la Carta ${ }^{63}$. Más recientemente, la Sala de apelaciones del Tribunal Penal Internacional para la antigua Yugoslavia estableció que incluso cuando actúa al amparo del capítulo VII, el Consejo de Seguridad ejerce una considerable discrecionalidad.

"Pero esto no significa que sus poderes sean ilimitados. El Consejo de Seguridad es un órgano de una organización internacional, establecida a través de un Tratado que opera como estructura constitucional de dicha organización. El Consejo de Seguridad está además sujeto a ciertas limitaciones constitucionales, al margen de lo amplios que sus poderes puedan ser según la constitución. Esos poderes no pueden, en ningún caso, ir más allá de los límites de la jurisdicción de la Organización en general, por no mencionar otras limitaciones específicas o aquellas que puedan derivarse de la división interna de poder en el seno de la Organización. En cualquier caso, ni el texto ni el espíritu de la

\footnotetext{
${ }^{60}$ Algunos autores interpretan que la Carta de Naciones Unidas establece un sistema en el que la paz está por encima de la justica y del Derecho internacional. Para un comentario y una crítica de esta visión, vide Elaraby (2003), especialmente, pp. 62-67.

${ }^{61}$ Frowein y Krisch (2002), p. 711 y De Wet (2004), pp. 133-177.

${ }^{62}$ Así, por ejemplo, la situación de emergencia y los principios que deben informar la actuación de los Estados en tales circunstancias descritos en el artículo 4 del Pacto Internacional de derechos civiles y políticos. Sobre esta cuestión, en general, Orấ (1992).

${ }^{63}$ Vide el caso relativo a las Consecuencias jurídicas que tiene para los Estados la continuación de la presencia de Sudáfrica en Namibia (CIJ, 1971), \$110. Igualmente, en el $\$ 115$ la CIJ recalca que las decisiones del Consejo de Seguridad eran conformes con los principios y propósitos de la Carta y eran "consecuentemente obligatorias para todos los Estados miembros de las Naciones Unidas, que tienen además la obligación de aceptarlas y ejecutarlas".
} 
Carta conciben al Consejo de Seguridad como legibus solutus (no vinculado por el Derecho)" "64.

Esta limitación derivada de la Carta Constitucional de Naciones Unidas ya fue reconocida por la Corte Internacional de Justicia:

"El carácter político de un órgano no puede eximirlo de la obligación de observar las disposiciones convencionales establecidas por la Carta cuando constituyen limitaciones a su poder o criterios para su motivación" ${ }^{65}$.

Lo anterior sugiere que incluso cuando actúa al amparo del capítulo VII, el Consejo de Seguridad debe adoptar tan sólo aquellas medidas que sean apropiadas para acabar con una amenaza o para suprimir un quebrantamiento de la seguridad internacional ${ }^{66}$. Por lo demás, los derechos humanos "ahora forman parte del concepto de orden público internacional" ${ }^{67}$.

\subsection{Los limites derivados del Derecho internacional}

18. Se puede entender que el Consejo de Seguridad está vinculado por el Derecho internacional de dos formas distintas. Por una parte, en tanto que órgano de las Naciones Unidas, que tiene reconocida personalidad en el ordenamiento jurídico internacional, el Consejo de Seguridad está obligado a respetar el Derecho internacional ${ }^{68}$. Para ser exactos, en principio, la ONU no estaría obligada a respetar los tratados internacionales sobre derechos humanos dado que no es signataria de dichos instrumentos. No obstante, la Organización sí que está vinculada por el Derecho internacional consuetudinario y por los principios generales del Derecho internacional, al menos en tanto en cuanto la Carta no disponga otra $\operatorname{cosa}^{69}$. Consecuentemente, el Consejo de Seguridad de la ONU quedaría exento de respetar la prohibición general del uso de la fuerza y de no intervención además de no estar sujeto a los principios generales del Derecho internacional en

\footnotetext{
${ }^{64}$ Prosecutor v. Tadić (TPI-Yugoslavia, 1995), \$28.

${ }^{65}$ Vide el Caso relativo a las condiciones de admisión de un Estado como miembro de las Naciones Unidas - artículo 4 de la Carta (CIJ, 1948), concretamente la p. 64.

${ }^{66}$ ReINISCH (2001), pp. 858-859.

${ }^{67}$ BRownlie (1994), p. 93.

${ }^{68}$ Sobre la personalidad jurídica de la ONU, vide el caso Reparación por daños sufridos al servicio de las Naciones Unidas (CIJ, 1949), concretamente, p. 179, esta decisión también es conocida como "caso Bernadotte". Para un análisis de esta cuestión, vide Gautier (2000), especialmente 337-341. Sobre la sujeción del Consejo de Seguridad al Derecho internacional vide la Interpretación del Acuerdo de 25 de marzo de 1951 entre la OMS y Egipto (CIJ, 1980), especialmente, pp. 89-90. BIANCHI (2006), especialmente, p. 886.

${ }^{69}$ SCHERMERS y BloKKer (2004), pp. 834 y 994.
} 
sus intervenciones para poner fin a las hostilidades que hubieran comenzado. Sin embargo, desde el punto de vista del Derecho internacional consuetudinario de los derechos humanos, la Carta parece solamente reafirmar la importancia que tienen los mencionados derechos en dichas operaciones y en la legitimidad de las acciones de la ONU. Y, así, mientras que muchas normas derivadas del Derecho internacional consuetudinario y de los principios generales del Derecho internacional han sido tradicionalmente de aplicación sólo a las acciones de los Estados, la ONU se entiende limitada ella misma de forma creciente por dichas normas, a medida que sus acciones se van aproximando a los esquemas de actuación de los poderes estatales ${ }^{70}$. La concreta configuración de los estándares internacionales sobre derechos humanos debería tener en cuenta el contexto específico en el que se desenvuelva la actividad de las Naciones Unidas en concreto, pero el principio general sobre la aplicabilidad de estas normas a la ONU en tanto que un actor internacional revestido de personalidad jurídica se mantiene ${ }^{71}$.

19. En segundo lugar, como ya ha tenido oportunidad de concluir alguna jurisdicción internacional para el caso de la Unión Europea, los Estados no pueden simplemente evitar la aplicación del Derecho internacional sobre derechos humanos a través de la creación de una organización a la que encargaran actividades y tareas que pudieran violar derechos humanos si fueran directamente ejercidas por los Estados miembros ${ }^{72}$. Una vez más, la aplicación de los estándares debe tener en cuenta el particular contexto internacional en que han de ser aplicados. Pero los miembros no pueden eludir los estándares de los derechos humanos trasladando la comisión de los abusos a la ONU. De esta afirmación, que algunos autores han bautizado como el "principio de no-elusión", se derivarían dos consecuencias ${ }^{73}$.

20. Así, por una parte, el "principio de no-elusión" significaría que los Estados siguen siendo objetivamente responsables por los abusos en materia de derechos humanos en los que pudiera incurrir una organización internacional que ellos dirigen y controlan o a la que han transferido competencias para que actúe en su

\footnotetext{
${ }^{70}$ Sobre la aplicación del Derecho internacional humanitario a las administraciones territoriales de la ONU, vide RATNER (2005).

${ }^{71}$ Vide Álvarez (2005), p. 180, donde sostiene que algunas disposiciones sobre derechos humanos no se podrían aplicar a la ONU sin modificación. Igualmente, vide Prosecutor vs. Tadić (TPI-Yugoslavia, 1995), $\$ 43-48$, donde se sostiene que el esquema tradicional de separación de poderes en el plano nacional no puede aplicarse tal cual en el ámbito internacional, pero que los principios generales sobre derechos humanos deben preservarse.

${ }^{72}$ Vide, entre otros, el caso Bosphorus v. Irlanda (TEDH, 2005), \$154. Para un análisis de esta cuestión, vide GORDILlo (2011).

${ }^{73}$ Halberstam y Stein (2009), p. 21. Los autores hablan del "principle of non-circumvention".
} 
nombre ${ }^{74}$. El proyecto de artículos sobre responsabilidad de las organizaciones internacionales elaborado por la Comisión de Derecho Internacional establece la siguiente disposición:

"Artículo 61. Elusión de obligaciones internacionales de un Estado miembro de una organización internacional.

1. Un Estado miembro de una organización internacional incurre en responsabilidad internacional si, prevaliéndose de que la organización es competente en relación con el objeto de una de las obligaciones internacionales del Estado, se sustrae al cumplimiento de la obligación induciendo a la organización a cometer un hecho que, de haber sido cometido por el Estado, habría constituido una violación de esa obligación.

2. El párrafo 1 se aplica independientemente de que el hecho sea o no internacionalmente ilícito para la organización internacional"75.

Este proyecto de artículo hace referencia al supuesto en el que un Estado elude una de sus obligaciones internacionales cuando se vale de la personalidad jurídica distinta de una organización internacional de la que es miembro. Aun cuando el Estado ya no controla las decisiones de la organización internacional puede, sin embargo, incurrir en responsabilidad internacional en virtud de haber aceptado voluntariamente estar obligado por las decisiones de la organización internacional en cuestión a través de un acto de Derecho interno ${ }^{76}$. La jurisprudencia del TEDH proporciona algunos ejemplos de Estados a los que se puede tener por responsables cuando han atribuido competencia a una organización internacional y no han velado por el cumplimiento de las obligaciones que les incumben en virtud del CEDH. En los asuntos Waite y Kennedy vs. Alemania y Beer y Regan vs. Alemania, por ejemplo, el TEDH examinó la cuestión de si el derecho de acceso

\footnotetext{
${ }^{74}$ Vide el Informe de la Comisión de Derecho Internacional de Naciones Unidas en su $63^{\circ}$ período de sesiones $(26 \mathrm{de}$ abril a 3 de junio y 4 de julio a 12 de agosto de 2011) que recoge la versión final del texto y título de los proyectos de artículo 1 a 67 sobre Responsabilidad de las organizaciones internacionales aprobados en segunda lectura por el Comité de Redacción en 2011. Vide, igualmente, los trabajos anteriores de la Comisión, especialmente el Informe de la Comisión de Derecho Internacional de Naciones Unidas, 58 período de sesiones (1 de mayo a 9 de junio y 3 de julio a 11 de agosto de 2006), el Informe de la Comisión de Derecho Internacional de Naciones Unidas, $61^{\circ}$ período de sesiones ( 4 de mayo a 5 de junio y 6 de julio a 7 de agosto de 2009), pp. $22-43$ y el análisis del relator especial Sr. Roberto Ago sobre el origen de la responsabilidad internacional, Ago (1970).

75 Vide el comentario del antiguo artículo 60 (finalmente, renumerado como artículo 61) en el Informe de la Comisión de Derecho Internacional de Naciones Unidas, 61º período de sesiones (2009), pp. 184-187, así como la Declaración del Presidente del Comité de 3 junio 2011, especialmente, pp. 39-40.

${ }^{76}$ Vide el caso Matthews vs. Reino Unido (TEDH, 1999) $\$ 32$ en el que el TEDH rechaza el argumento del Reino Unido según el cual los actos adoptados por la Comunidad a la que el Reino le había atribuido ciertas competencias no puede ser imputado al Estado. Sobre esta cuestión, vide SAROOSHI (2007), especialmente, pp. 101-107.
} 
a la jurisdicción había resultado indebidamente menoscabado por un Estado que concedió inmunidad a la Agencia Espacial Europea, de la que era miembro, en relación con demandas en materia de empleo. Aunque el Tribunal de Estrasburgo concluyó en este caso que no se había menoscabado la esencia del "derecho a un tribunal" del demandante reconocido en el CEDH, el TEDH recordó la imposibilidad de que al transferir competencias a organizaciones internacionales, los Estados contratantes quedaran exonerados de toda responsabilidad en relación con el Convenio en la esfera de actividad objeto de la atribución ${ }^{77}$.

A mayor abundamiento, si, además, el Estado participa directamente en la implementación de las decisiones y políticas de la organización internacional en cuestión y, por tanto, toma parte en la ejecución de actos que hubieran sido ilegales si hubieran sido adoptados por el Estado individualmente, es posible encontrar nuevos argumentos a favor de la responsabilidad del Estado. El proyecto de artículos sobre responsabilidad internacional de las organizaciones internacionales dispone en este sentido:

"Artículo 14. Ayuda o asistencia en la comisión de un hecho internacionalmente ilícito

La organización internacional que presta ayuda o asistencia a un Estado o a otra organización internacional en la comisión por ese Estado o por esta última organización de un hecho internacionalmente ilícito es responsable internacionalmente por prestar ayuda o asistencia si:

a) lo hace conociendo las circunstancias del hecho internacionalmente ilícito, y

b) el hecho sería internacionalmente ilícito si fuese cometido por la organización que presta la ayuda o asistencia"78.

En el asunto Bosphorus vs. Irlanda, el TEDH, haciéndose eco de una doctrina anterior de la Comisión (M. \& Co. vs. Alemania) dijo que un Estado no se podía liberar de las obligaciones que le incumbían en virtud del Convenio Europeo de Derechos Humanos mediante la transferencia de funciones a una organización internacional porque, de lo contrario, las garantías previstas en el Convenio podrían ser limitadas o excluidas discrecionalmente por los Estados ${ }^{79}$. En este caso, el TEDH fallaría finalmente que el Estado demandado no había

\footnotetext{
77 Vide el caso Beery Regan vs. Alemania (TEDH, 1999), $\$ 57$ y el caso Waite y Kennedy vs. Alemania (TEDH, 1999), \$67. Un punto de vista ya fue defendido mucho antes, vide Di BLASE (1974), especialmente, pp. 275-276.

${ }^{78}$ Vide el comentario a esta disposición en el Informe de la Comisión de Derecho Internacional de Naciones Unidas, $61^{\circ}$ período de sesiones (2009), pp. 92-95.

${ }^{79}$ Caso Bosphorus v. Irlanda (TEDH, 2005), \$154. Igualmente, vide el caso M. \&. Co. v. Alemania (Comisión Europea Derechos Humanos, 1990).
} 
incurrido en responsabilidad porque los derechos fundamentales pertinentes estaban protegidos en el ámbito de la Unión Europea "de una manera que puede considerarse al menos equivalente a la que prevé el Convenio", pero por primera vez entró de lleno a analizar un acto emanado por una organización internacional cuya validez se salvó estableciendo la controvertida teoría de la protección equivalente, lo que hace pensar que en caso de que el acto controvertido hubiera sido aprobado y ejecutado directamente por Irlanda sin conexión comunitaria alguna, el Estado en cuestión bien podría haber sido condenado por el TEDH ${ }^{80}$. El desarrollo de este principio de la responsabilidad de los Estados debería ocupar un lugar importante en la implementación de las decisiones del Consejo de Seguridad de congelar activos financieros de particulares o en la administración de los territorios internacionales ${ }^{81}$.

21. Por otra parte, el "principio de no-elusión" también querría decir que las organizaciones internacionales pueden, en ocasiones, considerarse a sí mismas vinculadas por las obligaciones a las que están sujetos sus Estados miembros. El principal argumento a favor de esta tesis vendría de la ya llamada teoría de la sucesión funcional ${ }^{82}$. Es decir, esta teoría básicamente vendría a significar que cuando una organización internacional pasa a ejercer las competencias que previamente correspondían a un Estado o un grupo de Estados en el contexto de un régimen jurídico internacional específico, entonces dicha organización internacional sucede a ese Estado (o grupo de Estados) no solamente en sus derechos sino también en las obligaciones derivadas de ese particular régimen jurídico internacional ${ }^{83}$. Al margen de su aplicación a la entonces Comunidad Europea (hoy UE) para justificar su vinculación a ciertos acuerdos de tipo comercial y aduanero, esta teoría tuvo su interés en el contexto de la sucesión de la Sociedad de Naciones por parte de la Organización de las Naciones Unidas ${ }^{84}$. Una aplicación parcial y limitada de este principio de la sucesión también puede ser hallado en el contexto de las administraciones territoriales de la $\mathrm{ONU}^{85}$.

\footnotetext{
${ }^{80}$ Bosphorus v. Irlanda (TEDH, 2005), \$155, vide el voto conjunto concurrente de los magistrados RozAKIS, Tulkens, Traja, Botoucharova, Zagrebelsky y Garlicki, especialmente $\$ 4$.

${ }^{81}$ De esta opinión son Halberstam y STEIN (2009), p. 22, aunque señalan el negativo precedente en su tesis que supone el caso Behrami.

${ }^{82}$ Vide Pescatore (1990).

${ }^{83}$ Thallinger (2007), especialmente, p. 1026 y ReInisch (2001), p. 858.

${ }^{84}$ Caso Situación jurídica internacional del África Sudoccidental (CIJ, 1950), especialmente, pp. 132-138, donde se estableció que correspondían a la ONU ciertos derechos de la Sociedad de Naciones derivados del mandato sobre África Sudoccidental en virtud de la sucesión.
}

${ }^{85}$ Vide STAHN (2008), pp. 492-496. 


\section{EL PODER SANCIONADOR Y LA TUTELA JUDICIAL EFECTIVA.}

22. Las medidas antiterroristas se han convertido en una de las principales actividades que despliega el Consejo de Seguridad, especialmente desde finales de los años noventa a través de las llamadas sanciones selectivas (targeted) o inteligentes (smart), dirigidas a determinadas personas, grupos o sectores, evitando así los amplios e ineficaces embargos generales a los Estados que acababan afectando más a la población civil que a los dirigentes contra los que se dirigían ${ }^{86}$.

23. El sistema de funcionamiento de este régimen sancionador comienza con una resolución del Consejo de Seguridad en la que se conmina a todos los Estados a congelar los fondos y otros activos financieros o recursos económicos de las personas y entidades designadas en las resoluciones, impedir la entrada en su territorio o el tránsito por él de las personas designadas e impedir el suministro, la venta y la transferencia, directos o indirectos, a las personas y entidades designadas, desde su territorio o por sus nacionales fuera de su territorio o mediante buques o aeronaves de su pabellón, de armas y materiales conexos de todo tipo ${ }^{87}$. Además, se establece un Comité de Sanciones integrado por miembros del Consejo de Seguridad que tiene como misión establecer y revisar periódicamente una lista de nombres y hacer un seguimiento del cumplimiento de las sanciones por parte de los Estados ${ }^{88}$. Cada resolución establece teóricamente un régimen sancionador autónomo, aunque en la práctica casi todos siguen los mismos principios. No obstante, cabría establecer dos tipos de sistemas en función del proceso de listado. Así, por ejemplo, la resolución No 1.267 (1999) sobre Al-Qaida mantiene una lista centralizada en el Consejo de Seguridad, mientras que la Resolución No 1.373 (2001) no crea una lista centralizada, sino que delega en listas independientes que los Estados o la propia Unión Europea mantienen ${ }^{89}$.

24. Centrándonos en el régimen más autónomo del Consejo de Seguridad, de acuerdo con las directrices del Comité de sanciones contra Al-Qaida y los taliba-

\footnotetext{
${ }^{86}$ Gowlland-Debbas (2004), pp. 7-17.

${ }^{87}$ Vide, por ejemplo, la Resolución No 1.267 (1999) relación con el régimen talibán, Osama bin Laden, Al-Qaeda y sus colaboradores.

${ }^{88}$ Vide, en particular, las "Directrices para la realización de su labor" del Comité del Consejo de Seguridad establecido en virtud de la Resolución No 1.267 (1999), de 15 de octubre de 1999, también conocido como Comité de sanciones contra Al-Qaida y los talibanes, aprobadas el 7 de noviembre de 2002 y modificadas el 10 de abril de 2003, el 21 de diciembre de 2005, el 29 de noviembre de 2006, el 12 de febrero de 2007 y el 9 de diciembre de 2008 [(Última consulta: 14 enero 2012). Disponible en <http://www.un.org/spanish/ sc/committees/1267/1267_guidelines_sp.shtml>].

${ }^{89}$ Report of the Analytical Support and Sanctions Monitoring Team on the outcome of the review described in paragraph 25 of resolution 1822 (2008) de 29 septiembre 2010.
} 
nes un particular puede presentar a su gobierno o al de su país de residencia una solicitud de revisión (exclusión de la lista) y ese gobierno debe comunicar con el gobierno del Estado proponente (el que solicitó la inclusión de esa persona en la lista). Si tras las oportunas consultas, los dos gobiernos no llegan a un acuerdo, el asunto se elevará al Comité de sanciones que se reunirá en privado y decidirá por consenso. El asunto puede ser, igualmente, referido al Consejo de Seguridad. El Comité tiene la obligación de actualizar la lista cuando reciba nueva información. A modo de excepción, los Estados pueden autorizar el levantamiento parcial de la congelación de fondos para sufragar gastos básicos, incluyendo alimentos, alquileres, hipotecas, medicamentos, tratamientos médicos, honorarios legales y algunos más, pero el Comité debe ser notificado previamente y puede oponerse a ello ${ }^{90}$. En ningún momento se plantea, no obstante, que el sancionado tenga derecho a plantear un recurso, condición imprescindible para la existencia de una auténtica tutela judicial efectiva.

Hasta el año 2006, no existía la posibilidad de que un particular pudiera tener contacto directo con las Naciones Unidas. El individuo dependía totalmente de la (buena) voluntad del gobierno de su Estado para defender su caso en el ejercicio de la protección diplomática. No obstante, en el ámbito del ordenamiento jurídico comunitario un individuo podría demandar a su gobierno ante un tribunal nacional si éste rehúsa ampararlo, recurriendo el acto nacional (o, en su caso, comunitario) de implementación de la sanción. Así, respondiendo a las críticas recaídas sobre el procedimiento de exclusión de la lista negra, el Consejo de Seguridad instó al Secretario General a establecer un "punto focal" en la Secretaría para recibir por primera vez peticiones provenientes de particulares o grupos ${ }^{91}$. Sin embargo, los procedimientos ante el punto focal no permiten al individuo participar ni personalmente ni a través de un representante o asesor legal en el proceso de revisión, ni requieren que la ONU o cualquiera de los gobiernos proporcione al solicitante ningún tipo de información, más allá de la situación en la que se encuentra su solicitud de exclusión de la lista. Así, siguiendo el proceso descrito en el texto de las directrices hecho público, la resolución de cualquier tipo de petición de un particular sigue siendo un proceso esencialmente diplomático en el que el individuo tiene un papel muy secundario ${ }^{92}$.

\footnotetext{
${ }^{90}$ Vide las "Directrices para la realización de su labor" del Comité del Consejo de Seguridad establecido en virtud de la resolución 1267 (1999). Igualmente, vide MilLer (2003), especialmente, pp. 49-50 y Hey (2005).

${ }^{91}$ Vide, por ejemplo, el caso Kadi v. Consejo (TPI, 2005), \$270 y la consiguiente Resolución No 1.730 (2006), de 19 diciembre. El "punto focal" se hizo operativo el 30 de marzo de 2007.

${ }^{92}$ Hasta junio de 2011, de las 25 peticiones para ser excluidos de la lista tramitadas a través del procedimiento del punto focal (relación con el comité de sanciones de Al Qaida) 3 particulares (de un total de 18) y 17 entidades (de un total de 22) fueron excluidos de la lista.
} 
Este proceso no comporta ningún tipo de garantía en materia de derechos de defensa para el particular afectado ${ }^{93}$.

25. Debido a la falta de transparencia, a los cuestionables niveles de protección de este procedimiento sancionador y a los litigios suscitados ante los tribunales europeos (especialmente el conocido caso Kadi ante el Tribunal de Luxemburgo), el Consejo de Seguridad adoptó la Resolución No 1.904 (2009) a través de la que creó la oficina del Ombudsman del Comité de Sanciones de Al-Qaida ${ }^{94}$. Así, desde el 4 de junio de 2010 (fecha del nombramiento de la responsable de la oficina), los incluidos en las listas pueden solicitar su exclusión a esta autoridad. Según la resolución que lo crea, la función del Ombudsman consiste en asesorar al Comité de Sanciones a la hora de analizar las peticiones de exclusión de la lista. No obstante, la función de esta autoridad, lejos de asimilarse a la de un órgano judicial, y de acuerdo con su denominación, se asemeja más bien a la de un mediador. Dentro del procedimiento de "des-listado" existe una fase llamada de "diálogo", en la que los interesados, los Estados, el equipo de supervisión y el Comité participan en un diálogo facilitado por el Ombudsman, que es quien traslada las preguntas, peticiones y respuestas de unos a otros. A pesar de haber supuesto un avance, este procedimiento a caballo entre la protección diplomática $\mathrm{y}$ una pseudo-tutela judicial, no puede asimilarse ni de lejos a un procedimiento con todas las garantías.

El Tribunal General (antiguo TPI) de la UE ha establecido recientemente que la creación del Ombudsman de la ONU no resuelve la falta de tutela judicial efectiva que observa en el procedimiento sancionador del Comité de sanciones. Así, tal y como el Tribunal europeo ha dejado sentado el Consejo de Seguridad aún no ha establecido un órgano independiente e imparcial encargado de resolver, "de hecho y de Derecho, los recursos interpuestos contra las decisiones individuales adoptadas por el Comité de Sanciones”. Además, la desclasificación de los elementos de prueba que pueden revelarse al interesado continúa dependiendo totalmente de la voluntad del Estado que propuso la inclusión de éste en la lista del Comité de Sanciones, y ningún mecanismo garantiza que el interesado disponga de suficientes elementos de información como para gozar de una defensa eficaz (ni siquiera que conozca la identidad del Estado que solicitó su inclusión en la lista del Comité de Sanciones). Es por todo ello que el Tribunal General

\footnotetext{
${ }^{93}$ Entre el 30 de junio de 2008 y el 31 de julio de 2010, el Comité de sanciones examinó 488 nombres de particulares, grupos y entidades sujetos a sanciones del Comité de Al-Qaida y los Talibanes y excluyó de la lista 45 nombres. Vide el informe Report of the Analytical Support and Sanctions Monitoring Team on the outcome of the review described in paragraph 25 of resolution 1822 (2008) de 29 septiembre 2010, p. 4.

${ }^{94}$ WiLlis (2011), especialmente, pp. 737-745.
} 
concluye que "la creación del punto focal y del Ombudsman no puede asimilarse al establecimiento de un recurso jurisdiccional efectivo contra las decisiones del Comité de Sanciones" ${ }^{\prime 9}$.

\section{HaCia LA CONSTITUCIONALIZACIÓN DEL PODER Sancionador del Consejo de Seguridad}

26. Otra posibilidad para limitar el poder del Consejo de Seguridad y condicionar su acción al respeto de los derechos humanos dependerá en buena medida de una evolución que apenas ha comenzado. La tesis sería que en la medida en la que los poderes de las Naciones Unidas aumentan -y especialmente en el sentido de asumir competencias que hasta ahora ejercían los Estados- la Organización asimilará ciertos principios relativos a la protección de derechos humanos y la forma de ejercer el poder que tomará de las tradiciones constitucionales de sus Estados miembros y de otros instrumentos internacionales que no la vinculan directamente para fortalecer su propia legitimidad y la de los actos que emana ${ }^{96}$. Es decir, la ONU elegiría "libremente" el camino de la autolimitación de su poder a través de unos principios de naturaleza constitucional para, al igual que otras organizaciones internacionales hicieron en su momento (por ejemplo la Comunidad Europea, luego UE), legitimar su poder y, de paso, proporcionar argumentos a favor de la validez de sus actos a las instancias jurisdiccionales que eventualmente controlen sus acciones ${ }^{97}$. Pero hay que advertir que este proceso de asimilación de principios constitucionales no es un óbice para la aplicación de las normas internacionales sobre derechos humanos a las Naciones Unidas en virtud de otro tipo de vinculación jurídica (vide supra). Esto es, no se rechaza la naturaleza obligatoria del Derecho internacional de los derechos humanos. Sin embargo, en tanto que una fuente suplementaria e independiente de derechos fundamentales, la progresiva asimilación de principios constitucionales diferiría de las fuentes de Derecho internacional tradicionales. La naturaleza jurídica de este proceso sería pues, distinta de la adhesión a tratados internacionales, de la obligatoriedad del Derecho internacional consuetudinario o de los principios generales del Derecho internacional. También sería un caso distinto del que resultaría de la aplicación de la sucesión internacional o de la delegación de poderes condicionada al respeto de

\footnotetext{
${ }^{95}$ Caso Kadi v. Comisión (TG, 2010), \$128. Vide Simon (2010).

${ }^{96}$ Halberstam y STein (2009), p. 24. Los autores llaman a esta idea "Constitutional absorption" que bien podría traducirse por "asimilación constitucional".

${ }^{97}$ Sobre el compromiso unilateral con ciertos principios por parte de la administración territorial de Naciones Unidas, vide STAHN (2008), pp. 481-484.
} 
unos principios preestablecidos. El proceso que aquí se describe, por el contrario, implicaría la incorporación de principios de protección de derechos fundamentales emanados de los instrumentos jurídicos internacionales sobre la materia y, siguiendo la expresión ya utilizada en la jerga comunitaria, las tradiciones constitucionales comunes de sus Estados miembros. Así, estos principios, una vez asumidos por la Organización, tendrían un desarrollo distinto en el contexto de las Naciones Unidas. Es decir, la ONU, tras efectuar un análisis comparativo de los sistemas constitucionales de sus Estados miembros y de los tratados internacionales sobre la materia, extraería unos principios que posteriormente asumirían como propios los órganos que integran su estructura institucional y que constituirían una fuente independiente de legitimidad de sus actos.

27. La práctica reciente de Naciones Unidas podría sugerir que, efectivamente, la asimilación de ciertos principios está ya en marcha. La fuente de la que se están tomando está, sin embargo, limitada al Derecho internacional. Por ejemplo, en respuesta al requerimiento del Consejo de Seguridad de Naciones Unidas de que la Misión de Administración Provisional de las Naciones Unidas en Kosovo (UNMIK, en sus siglas en inglés) proteja los derechos humanos en Kosovo -resolución 1244 (1999)-, el Secretario General estableció en su informe:

"En el cumplimiento de sus responsabilidades, la UNMIK se guiará por las normas internacionalmente reconocidas de derechos humanos y se basará en ellas para ejercer su autoridad en Kosovo. La UNMIK incorporará una "cultura" de derechos humanos en todas sus esferas de actividad y adoptará políticas de derechos humanos a los fines de sus funciones administrativas"98.

Poco tiempo después, el primer reglamento aprobado por la UNMIK estableció en su articulado:

"Sección 2. Respeto de los estándares reconocidos internacionalmente

$\mathrm{Al}$ ejercer sus funciones, todas las personas que desempeñen funciones públicas o ejerzan cargos públicos en Kosovo respetarán los estándares en materia de derechos humanos reconocidos internacionalmente y no discriminarán a nadie por razón de sexo, raza, color, lengua, religión, opiniones políticas o de otro tipo, origen nacional, étnico o social, asociación con alguna comunidad nacional, propiedad, racionamiento u otro estatus" $"$.

${ }^{98}$ Informe del Secretario General sobre la Misión de Administración Provisional de las Naciones Unidas en Kosovo, 12 julio 1999, $\$ 42$.

${ }^{99}$ Reglamento núm. 1999/1, UNMIK/REG/1999/1, de 25 julio 1999, sobre la autoridad de la administración interina en Kosovo. 
Esta primera norma fue rápidamente seguida por otra regulación más genérica sobre el Derecho aplicable en Kosovo que incorporaba al ordenamiento del territorio bajo administración de la ONU toda una batería de Convenios internacionales en materia de protección de derechos humanos y que abolió la pena de muerte $^{100}$. De la misma forma, la Administración de Transición de las Naciones Unidas para Timor Oriental (UNTAET, en sus siglas en inglés) promulgó normas prácticamente idénticas sobre la forma en que los funcionarios y agentes públicos debían acometer sus trabajos ${ }^{101}$. Igualmente, el 6 de agosto de 1999, el Secretario General del momento promulgó un boletín "con el objeto de establecer principios y normas fundamentales del derecho internacional humanitario aplicables a las fuerzas de las Naciones Unidas que realizan operaciones bajo el mando y control de las Naciones Unidas" ${ }^{102}$. Sin establecer expresamente si las Naciones Unidas están o no directamente vinculadas por el Derecho internacional humanitario, el documento establece normas que reiteran lo esencial de las normas de Derecho internacional humanitario insertas en los cuatro Convenios de Ginebra de 1949 y los dos Protocolos de 1977 adicionales a éstos, que son los principales instrumentos de derecho humanitario ${ }^{103}$. También la Asamblea General ha sido activa en este ámbito, por ejemplo, con sus estrategias transversales para promover la igualdad de género en todas sus áreas de trabajo y fiscalizando e, incluso, censurando al Consejo de Seguridad por el impacto de sus programas de sanciones en los derechos humanos ${ }^{104}$.

28. Aunque algunos ven en estas acciones una confirmación de que la ONU está sujeta al cumplimiento de las garantías internacionalmente reconocidas en materia de derechos humanos, otros permanecen escépticos sobre si es una cuestión de vinculación jurídica o una aceptación graciosa y voluntaria de responsabilidad

\footnotetext{
${ }^{100}$ Reglamento núm. 1999/24, UNMIK/REG/1999/24, de 12 diciembre 1999, sobre el Derecho aplicable en Kosovo. Esta disposición sería modificada por el Reglamento núm. 2000/59, UNMIK/REG/2000/59, de 27 octubre 2000. Igualmente, hay que tener en cuenta el Reglamento núm. 2001/9, UNMIK/REG/2001/9, de 15 mayo 2001, por el que se establece el Marco constitucional para el autogobierno provisional, y modificado por el Reglamento núm. 2002/9, UNMIK/REG/2002/9 y por el Reglamento núm. 29/2007, UNMIK/REG/2007/29.

${ }^{101}$ Reglamento núm. 1999/1, UNTAET/REG/1999/1, de 27 noviembre, sobre la autoridad de la Administración de transcición en Timor Oriental.

${ }^{102}$ Vide el preámbulo del Boletín del Secretario General. Observancia del derecho internacional humanitario por las fuerzas de las Naciones Unidas, de 6 agosto 1999.

${ }^{103}$ En este sentido, vide RATNER (2005), p. 705.

${ }^{104}$ Álvarez (2005), p. 169.
} 
que, por tanto, sería reversible y estaría lejos de ser exigible jurídica o jurisdiccionalmente ${ }^{105}$. A pesar de que muchas de estos documentos incorporen derechos que, ciertamente, exceden de las normas tradicionales sobre derechos humanos (por ejemplo, los reglamentos de UNMIK y UNTAET que prohíben la pena de muerte), sin embargo estas declaraciones parecen representar primeros pasos en un proceso de asimilación de principios constitucionales largo y complejo que no habría hecho sino empezar. Si estos primeros pasos son seguidos por nuevas declaraciones (que, en última instancia, podrían ser promulgadas con efectos jurídicos plenos) y referencias específicas a normas internaciones, poco a poco, se podría ir conformando un acervo normativo y unas prácticas tales que serían susceptibles de ir calando en las normas que regulan el funcionamiento de las Naciones Unidas hasta convertirse en plenamente vinculantes ${ }^{106}$.

29. Esta idea de la progresiva asimilación de principios constitucionales por parte de las Naciones Unidas, evidentemente, está inspirada de forma directa en la evolución de la protección de los derechos fundamentales en la Unión Europea ${ }^{107}$. La Comunidad Europea, a través de su Tribunal de Justicia, desarrolló garantías en materia de derechos fundamentales antes de la aprobación del Tratado de Maastricht, cuando la protección de estos derechos quedó finalmente incorporada en el articulado del Tratado fundacional de la Unión Europea (artículo 6 TUE y TUE-L). La Comunidad Europea desarrolló derechos que cuyo alcance iba más allá de las normas consuetudinarias internacionales clásicas o de los principios generales del Derecho internacional. Y lo hizo desarrollando derechos fundamentales de forma autónoma imponiéndose, de esta forma, límites al ejercicio de su propio poder. Finalmente, la Comunidad Europea (luego UE) desarrolló estos principios no simplemente tomándolos tal cual de los distintos ordenamientos de sus Estados miembros, sino que el Tribunal de Justicia interpretó y construyó la categoría de las tradiciones constitucionales comunes que, junto con el Convenio Europeo de Derechos Humanos se incorporaría al ordenamiento constitucional de la Unión Europea a través de los principios generales del Derecho ${ }^{108}$.

\footnotetext{
${ }^{105}$ Entre los que ven una confirmación de que la ONU queda vinculada por los derechos humanos, vide De Wet (2004), especialmente, p. 320. Para un punto de vista más escéptico, vide Álvarez (2005), especialmente p. 171 y p. 179.

${ }^{106}$ En este sentido, vide Ratner (2005), pp. 705-706 y Álvarez (2005), pp. 88-89.

${ }^{107}$ Sobre esta cuestión, la bibliografía es casi inabarcable. Para una visión completa y exhaustiva del desarrollo de la protección de los derechos fundamentales en el texto comunitario vide WeILER (1991) o, más recientemente, CANEDO y GoRDILlo (2008).

${ }^{108}$ Halberstam (2005), especialmente pp. 800-801.
} 


\section{CONCLUSIONES}

30. Con los análisis anteriores (en los que se critican las carencias de la ONU en comparación con la UE) no se está sugiriendo que las Naciones Unidas vayan alguna vez a convertirse en una entidad política con un nivel de integración comparable a la Unión Europea ni que los Estados miembros de la ONU renuncien a acometer procesos de renovación de la Organización a través de los procedimientos tradiciones (reforma de tratados, por ejemplo) que aumenten y refuercen su legitimidad. Lo que se apunta es que dado que los poderes de las Naciones Unidas se están incrementando de forma continua y paulatina, y dado que la ONU está comenzando a ejercer competencias que hasta ahora estaban reservadas a los Estados (v.gr. sanciones dirigidas a individuos), sería deseable que la expansión del poder de la ONU se viera acompañada de un incremento proporcional de los niveles de garantía y protección de los derechos humanos por parte de sus órganos, para reforzar así la legitimidad del ejercicio de su poder, en particular, y la autoridad de Organización en la escena internacional, en general.

31. Algunos parecen lamentar los actos de autolimitación porque difuminarían el necesario reconocimiento de la naturaleza obligatoria del Derecho internacional consuetudinario en materia de derechos humanos. Sin embargo, este proceso de asimilación de principios constitucionales permitiría a una organización internacional como las Naciones Unidas desarrollar un catálogo específico de derechos adaptado a la naturaleza de sus objetivos y competencias que pudiera fortalecer tanto la propia organización y su legitimidad como la defensa de los derechos humanos. Este proceso sería susceptible de avanzar a través del camino ya iniciado por el Derecho consuetudinario internacional de los derechos humanos y las más bien limitadas tradiciones constitucionales que pudieran ser comunes entre la amplia variedad de miembros de la Organización. Este proceso proveería de la autonomía y flexibilidad necesarias para adaptar los esquemas tradicionales de protección de los derechos fundamentales propios de los Estados a los nuevos programas de sanciones establecidos por el Consejo de Seguridad, a los procesos jurisdiccionales de los tribunales y órganos creados ad hoc por el Consejo y a las administraciones territoriales dirigidas por la ONU. Este proceso no debe servir para disolver o vaciar de contenido los derechos fundamentales según las concepciones tradicionales. En el caso del derecho a la propiedad privada, por ejemplo, incluso sin llegar a un nivel de protección dictado por las normas generales de Derecho internacional consuetudinario o las tradiciones constitucionales comunes de los numerosos y distintos miembros de la ONU, dicho derecho debería, no obstante, integrarse en el Derecho de las Naciones Unidas como principio de naturaleza constitucional. Así, en tanto que principio básico que ha de ser 
respetado por la ONU y sus órganos, este principio gozaría de una flexibilidad tal que le permitiría ser aplicado por parte de la administración territorial de la ONU en zonas inestables o en transición y, al mismo tiempo, fundamentaría una mayor protección, desde el punto de vista tanto material como procedimental, en el contexto de las sanciones económicas "inteligentes".

32. El procedimiento de exclusión de los listados del Comité de Sanciones Al-Qaida ha mejorado sustancialmente, incluyendo una suerte de asistencia a los solicitantes, con lo que se va abandonando la zona gris de la protección diplomática y los métodos impersonales de los puntos focales. Sin embargo, este tipo de mediación institucionalizada, que incluso cabría denominar como "negociación asistida", no puede ser en ningún caso (parafraseando la jurisprudencia Bosphorus) "equivalente" ni "comparable" a un auténtico proceso con todas las garantías, tal y como está reconocido por la Declaración Universal, el CEDH, el Derecho de la UE o los Derechos constitucionales de los Estados democráticos.

33. Por otra parte, en aras de reducir la inestabilidad en las relaciones entre ordenamientos (Constitución nacional, Tratados Internacionales -Derecho de la UE, CEDH... -, Derecho de la ONU) y, sobre todo, para garantizar la fuerza vinculante de las sanciones, el Consejo de Seguridad haría bien en irse adecuando paulatinamente y en la medida de lo posible a los estándares de protección de la UE y del CEDH. Si no lo hace, tanto el Tribunal de Justicia como el TEDH (o incluso los tribunales supremos y constitucionales nacionales) se plantearán someter a un control de "constitucionalidad", "comunitariedad" o "convencionalidad" a las sanciones de la ONU, para reafirmar así su propia legitimidad frente a sus ciudadanos. Es decir, si los niveles de protección de los derechos de los sancionados siguen siendo tan bajos, no sería descartable (caso Kadi, casos Solange) que algún tribunal nacional o supranacional esté tentado de reconocerse competente para controlar dichas sanciones y erigirse así en guardián de los derechos fundamentales de sus ciudadanos, ya que la ONU se muestra incapaz de hacerlo. Al dar ese paso adelante, y dada la falta de institucionalización de las Naciones Unidas, los Estados y las otras organizaciones internacionales pondrían en entredicho el Derecho y la propia existencia de las Naciones Unidas más allá de un mero foro político internacional. Todo ello, sin entrar a valorar el hecho de que la situación actual contribuye a una mayor fragmentación del Derecho Internacional (una suerte de Wild-West-World) que pone en duda el carácter jurídico de la propia ONU, la obligatoriedad de su ordenamiento y la seguridad jurídica internacional.

Por todo lo anterior, la conclusión fundamental de este trabajo es que la ONU es la primera interesada en aumentar los estándares de protección de derechos en los procesos sancionadores. 


\section{BiBLIOGRAFÍA}

ABI-SAAB, G. (2001): "The Concept of Sanction in International Law", en GowLLAND-Debbas, V. (ed.) United Nations Sanctions and International Law (The Hague, Kluwer Law International, 2001) pp. 29-41.

AGo, R. (1970): "Second report on State responsibility. The origin international responsibility", en Yearbook of the International Law Commission, (Vol. II), pp. 177-197.

ÁlvareZ, J. E (2005): International Organizations As Law-makers (Oxford, University Press).

Andersson, T., Cameron, I., Nordback, K. (2003): "EU blacklisting: the renaissance of imperial power, but on a global scale", en European Business Law Review (Vol. 14, Issue 2), pp. 111-141.

Baldwin, D. A. (1999): "The Sanctions Debate and the Logic of Choice", en International Security (Vol. 24, Issue 3), pp. 80-107.

Berman, P. S. (2007a): "A pluralist approach to international law", en The Yale Journal of International Law (Vol. 32, Issue 2), pp. 301-330.

Berman, P. S. (2007b): “Global Legal Pluralism”, en Southern California Review (Vol. 80 Issue 6), pp. 1155-1238.

BiAnCHI, A. (2006): "Assessing the Effectiveness of the UN Security Council's Antiterrorism Measures: The Quest for Legitimacy and Cohesion", en European Journal of International Law (Vol. 17, Issue 5), pp. 881-919.

Bothe, M. (2008): "Security Council's Targeted Sanctions against Presumed Terrorists: The Need to Comply with Human Rights Standards", en Journal of International Criminal Justice (Vol. 6, Issue 3), pp. 541-555.

Braillard, P., Djalili, M. R. (1992): Les relations internationales (Paris, PUF).

Brandtner, B., Rosas, A. (1998): "Human Rights and the External Relations of the European Community: An Analysis of Doctrine and Practice", en European Journal of International Law (Vol. 9, Issue 3), pp. 468-490.

Brownlie, I. (1994): "The decisions of political organs of the United Nations and the rule of law", en Macdonald, R. S. J. Essays in honour of Wang Tieya (Dordrecht, Martinus Nijhoff), pp. 91-102.

Buffard, I., Crawford, J., Pellet, A., Wittich, S. (2008): International Law between universalism and fragmentation: Festschrift in honour of Gerhard Hafner (Martinus Nijhoff, Leiden).

CAMERON, I. (2003): "UN Targeted Sanctions, Legal Safeguards, and the ECHR", en Nordic Journal of International Law (Vol. 72), pp. 159-214. 
Canedo Arrillaga, J. R., Gordillo Pérez, L. I. (2008): "Los derechos fundamentales en la Unión Europea a la espera de Lisboa", en Cuadernos Europeos de Deusto (núm. 39), pp. 27-59.

CANOR, I. (1998): "Can two walk together, except they be agreed? The relationship between international law and European law: The incorporation of United Nations sanctions against Yugoslavia into European Community law through the perspective of the European Court of Justice", en Common Market Law Review (Vol. 35, Issue 1), pp. 137-188.

Conen, J. L. (2008): "A Global State of Emergency or the Further Constitutionalization of International Law: A Pluralist Approach", en Constellations (Vol. 15, Issue 4), pp. 456-484.

Colliard, C., Dubois, L (1995): Institutions internationales (Paris, Dalloz).

Cortright, D., Lopez, G. A. (2000): The Sanctions Decade: Assessing UN Strategies in the 1990s (London, Lynne Rienner).

Cortright, D., Lopez, G. A. (2002): Sanctions and the Search for Security: Challenges to UN Action (London, Lynne Rienner).

Cover, R. (1981): "The Uses of Jurisdictional Redundancy: Interests, Ideology and Innovation", en William \& Mary Law Review (Vol. 22, Issue 4), pp. 639-682.

Crawford, J. (2002): The International Law Commission's Articles on State Responsibility: Introduction, Text and Commentaries (Cambridge, University Press).

CRAWFord, J. (2005): Los artículos de la Comisión de Derecho Internacional sobre la Responsabilidad Internacional del Estado: Introducción, texto y comentarios (Madrid, Dykinson).

De Búrca, G. (2010): "The European Court of Justice and the International Legal Order After Kadi”, en Harvard International Law Journal (Vol. 51, Issue 1), pp. 1-49.

De Wet, E. (2001): "Human Rights Limitations to Economic Enforcement Measures Under Article 41 of the United Nations Charter and the Iraqi Sanctions Regime", en Leiden Journal of International Law (Vol. 14), pp. 277-300.

De Wet, E. (2004): The Chapter VII Powers of the United Nations Security Council (Oxford, Hart).

Denis, C. (2004): Le pouvoir normatif du Conseil de Sécurité des Nations Unies: portée et limites (Bruxelles, Bruylant).

Di BLASE, A., "Sulla responsabilità internazionale per attività dell'ONU", Rivista di Diritto Internazionale, Vol. 57, 1974, pp. 250-280.

Douglas-Scott, S. (2006): "Bosphorus Hava Yollari Turizm Ve Ticaret Anonim Şirketi v. Ireland”, en Common Market Law Review (Vol. 41, Issue 3), pp. 243-254. 
DoXeY, M. (1996): International Sanctions in Contemporary Perspective, ( $2^{\text {nd }}$ ed., New York, St. Martin's Press).

ECKES, C. (2007): "Case T-228/02, Organisation des Modjahedines du peuple d'Iran v. Council and UK (OMPI)", en Common Market Law Review (Vol. 44 Issue 4), pp. 1117-1129.

Elaraby, N. (2003): "Some Reflections on The Role of the Security Council and the Prohibition of the Use of Force in International Relations: Article 2(4) Revisited in Light of Recent Developments", en FroweIn, J. A. et allii, Verhandeln für den Frieden/ Negotiating for peace. Liber amicorum Tono Eitel (Berlin, Springer), pp. 41-67.

Elliott, K. A. (1998): “The Sanctions Glass: Half Full or Completely Empty?", en International Security (Vol. 23, Issue 1), pp. 50-65.

Farrall, J. M. (2007): United Nations Sanctions and the Rule of Law (Cambridge University Press).

Fitzgerald, P. L. (1999): "If Property Rights Were Treated Like Human Rights, They Could Never Get away with This: Blacklisting and Due Process in U.S. Economic Sanctions Programs", en Hastings Law Journal (Vol. 51, Issue 1), pp. 73-169.

Fitzgerald, P. L. (2002): "Managing "Smart Sanctions" Against Terrorism Wisely", en New England Law Review (Vol. 36, Issue 4), pp. 957-983.

Fremuth, M., Griebel, J. (2007): "On the Security Council as a Legislator: A Blessing or a Curse for the International Community?", en Nordic Journal of International Law (Vol. 76, Issue 4), pp. 339-361.

Frowein, J. A., Krisch, N. (2002): "Introduction to Chapter VII, Articles 39-43", en Simma, B. (ed.) The Charter of the United Nations: A Commentary $\left(2^{\text {nd }}\right.$ ed., Oxford University Press), pp. 701-763.

Gautier, P. (2000): “The Reparation for Injuries Case Revisited: The Personality of the European Union", en Max Planck Yearbook of United Nations Law (Vol. 4), pp. 331-361.

GoRdillo PÉREZ, L. I. (2005): "El proceso de integración europea y la teorización de la dinámica comunitaria", en Iuridica (núm. 2), pp. 47-80.

Gordillo Pérez, L. I. (2011): "Un paso más hacia la estabilización de las relaciones interordinamentales en Europa: la incorporación de la UE al CEDH”, en Revista Española de Derecho Europeo (núm. 38), pp. 173-204.

Gordillo Pérez, L. I. (2012): Interlocking Constitutions. Towards an Interordinal Theory of National, European and UN Law (Oxford, Hart).

Gowlland-Debbas, V. (2001): United Nations Sanctions and International Law (The Hague, Kluwer Law International). 
Gowlland-Debbas, V. (2004): "Sanctions Regimes under Article 41 of the Charter", en Gowlland-Debbas, V. (ed.) National implementation of United Nations sanctions: a comparative study (Leyden, Martinus Nijhoff Publishers), pp. 3-31.

Grant, R. W., Keohane, R. O. (2005): "Accountability and Abuses of Power in World Politics", en American Politcal Science Review (Vol. 99, Issue 1), pp. 29-43.

Halberstam, D. (2005): "The Bride of Messina: Constitutionalism and Democracy in Europe", en European Law Review (Vol. 30, Issue 6), pp. 775-801.

Halberstam, D. (2010): "Pluralism in Marbury and Van Gend", en MADURO, M. P., Azoulai, L., The Past and the Future of EU Law: Revisiting the Classics on the 50th Anniversary of the Rome Treaty (Oxford, Hart), pp. 26-36.

Halberstam, D., Stein, E. (2009): "The United Nations, the European Union, and the King of Sweden: Economic sanctions and individual rights in a plural world order", en Common Market Law Review (Vol. 46, Issue 1), pp. 13-72.

Hale, T. N. (2008): "Transparency, Accountability and Global Governance", en Global Governance (Vol. 14, Issue 1), pp. 73-94.

Hansen, L., Williams, M. (2002): "The Myths of Europe: Legitimacy, Community and the 'Crisis' of the EU', en Journal of Common Market Studies (Vol. 37, Issue 2), pp. 233-249.

Hey, E. (2005): "The High-level Summit, International Institutional Reform and International Law", en Journal of International Law \& International Relations (Vol. 2 Issue 1), pp. 5-25.

Hilaire, M. (2005): United Nations Law and the Security Council (Surrey, Ashgate).

Hinojosa Martínez, L. M. (2008): “The Legislative Role of the Security Council in its fight against Terrorism: Legal, Political and Practical Limits", en International and Comparative Law Quarterly (Vol. 57, Issue 2), pp. 333-359.

Horeth, M. (1999): "No way out for the Beast? The Unsolved Legitimacy Problem of European Governance", en Journal of European Public Policy (Vol. 6, Issue 2), pp. 249-268.

Kelsen, H. (1965): Principios de Derecho Internacional Público (Traducción del original publicado en inglés en 1952 por Hugo Caminos y Ernesto C. Hermida, Buenos Aires, Ateneo).

Kennedy, D. (2007): “One, Two, Three, Many Legal Orders: Legal Pluralism and the Cosmopolitan Dream", en New York University Review of Law and Social Change, (Vol. 31, Issue 3), pp. 641-660.

Keohane, R. O. (2003): "Global Governance and Democratic Accountability", en Held, D., Koenig-Archibugi, M. (eds.), Taming Globalization: Frontiers of Governance (London Polity Press), pp. 130-159. 
Keohane, R. O., Nye, J. S. (2003): "Redefining Accountability for Global Governance”, en KAHLER, M., LAKE, D. A. (eds.), Governance in a Global Economy: Political Authority in Transition (Princeton University Press), pp. 386-411.

Knoll, B. (2007), "Too Little, Too Late: The Human Rights Advisory Panel in Kosovo", en European Human Rights Law Review (Vol. 7, Issue 5), pp. 534549.

Koskenniemi, M. (1995): “The Police in the Temple Order, Justice and the UN: A Dialectical View", en European Journal of International Law (Vol. 6, Issue 1), pp. 325-348.

Koskenniemi, M., Leino, P. (2002): "Fragmentation of International Law? Postmodern Anxieties", en Leiden Journal of International Law (Vol. 15, Issue 3), pp. 553-579.

KRISCH, N. (2006): “The Pluralism of Global Administrative Law”, en European Journal of International Law (Vol. 17, Issue 1), pp. 247-278.

Lalive, J. F. (1954): "L'immunité de juridiction des Etats et des organisations internationales", en Recueil des cours de l'Académie de Droit International de la Haye (Vol. 84, 1953-III), pp. 210-396.

Mariscal BerÁstegui, N. (2003): Teorías políticas de la integración europea (Madrid, Tecnos).

Meijers, E. M. (1970): "L'histoire des principes fondamentaux du droit international privé à partir du Moyen Age, spécialement dans l'Europe occidentale", en Recueil des cours de l'Académie de Droit International de la Haye (Vol. 49, 1934-III), pp. 543-686.

Miller, E. (2003): "The Use of Targeted Sanctions in the Fight against International Terrorism: What about Human Rights?", en American Society of International Law Proceeding (Vol. 97), pp. 46-51.

MonaCo, R. (1965): Lezioni di organizzazione internazionale i diritto delle istituzioni internazionali (Torino, Giappichelli).

Morgenstern, F. (1986): Legal Problems of International Organizations (Cambridge University Press).

Müller, J. P., Kolb, R. (2002): “Article 2.2”, en SIMMA, B. (ed.), The Charter of the United Nations: A Commentary (2nd ed., Oxford University Press), pp. 91-100.

Odvar, E., Fossum, J., E. (2004): "Europe in Search of Legitimacy: Strategies of Legitimation Assessed”, en International Political Science Review (Vol. 25), pp. 435-459.

OraÁ OraÁ, J. (1992): Human Rights in States of Emergency in International Law (Oxford, Clarendon). 
ÖsterdaHL, I. (1998): Threat to the Peace: the interpretation by the Security Council of Article 39 of the UN Charter (Uppsala, Iustus).

Pape, R. A. (1997): "Why Economic Sanctions Do Not Work", en International Security (Vol. 22, Issue 2), pp. 90-136.

Pape, R. A. (1998): "Why Economic Sanctions Still Do Not Work", en International Security (Vol. 23, Issue 1), pp. 66-77.

Pastor Ridruejo, J. A. (2010): Curso de Derecho internacional Público y Organizaciones internacionales (13 a ed., Madrid, Tecnos).

Pérez Vera, E. (1977): "Reflexiones sobre los procesos de integración regional", en Revista de Instituciones Europeas (Vol. 4, Issue 3), pp. 669-700.

Pescatore, P. (1990): "La Cour de Justice des Communautés Européenes et la Convention Européenne des Droits de l'Homme”, en Wiarda, G. J., MatsCher, F. \& Petzold, H. (coords.) Protecting human rights, the European dimension: studies in honour of / Protection des droits de l'homme, la dimension européenne. Mélanges en l'honneur de Gérard J. Wiarda (2e éd., Köln, C. Heymann), pp. 441-454.

Picchio Forlati, L., Sicilianos, L. A. (2004): Economic Sanctions in International Law/Les sanctions économiques en droit International (Leyden, Martinus Nijhoff Publishers).

Randelzhofer, A. (2002): "Article 2", en Simma, B. (ed.) The Charter of the United Nations: A Commentary (2nd ed., Oxford University Press), pp. 64-68.

RATNER, S. R. (2005): "Foreign Occupation and International Territorial Administration: The Challenges of Convergence", en European Journal of International Law (Vol. 16, Issue 4), pp. 695-719.

ReICH, J. (2010): "Due Process and Sanctions Targeted Against Individuals Pursuant to Resolution 1267 (1999)", en Yale Journal of International Law (Vol. 33, Issue 2), pp. 505- 510.

Reinisch, A. (2000): International Organizations Before National Courts (Cambridge University Press).

Reinisch, A. (2001): "Developing Human Rights and Humanitarian Law Accountability of the Security Council for the Imposition of Economic Sanctions", en American Journal of International Law (Vol. 95, Issue 4), pp. 851-871.

Rey Aneiros, A. (2008): “TEDH Resolución de admisibilidad de 02.05.2007, Behrami y Behrami c. Francia, 71412/01, y Saramati c. Francia, Alemania y Noruega, 78166/01", en Revista de Derecho Comunitario Europeo (núm. 30), pp. 511-526.

SARI, A. (2008): "Jurisdiction and International Responsibility in Peace Support Operations: The Behrami and Saramati Cases", en Human Rights Law Review (Vol. 8, Issue 1), pp. 151-170. 
SAROOSHI, D. (2007): International Organizations and Their Exercise of Sovereign Powers (Oxford University Press).

Scheppele, K. L. (2006b): "The Migration of Anti-Constitutional Ideas: The Post-9/11 Globalization of Public Law and the International State of Emergency", en Choudhry, S. (ed.) The Migration of Constitutional Ideas (Oxford University Press), pp. 347-373.

SCHEPpele, K. M. (2006a): "The International State of Emergency: Challenges to Constitutionalism after September 11", en Digital Commons UM Law (Paper 49, University of Maryland School of Law).

Schermers, H. G. (1991): "Les organisations internationales" en Bedjaoui, M. (dir.), Droit international. Bilan et perspectives (Paris, Pedone), Vol. I, pp. 69105.

SCHERMERs, H. G., BlOKKER, N. M. (2004): International Institutional Law: Unity Within Diversity (4th ed., The Hague, Martinus Nijhoff).

Schrijver, N. J. (1999): "Interpreting the Principles and Purposes of the United Nations", en Van Krieken, P. J. (ed.) Refugee Law in Context. The Exclusion Clause (The Hague, T.M.C. Asser Institute).

Simon, D. (2010): "Sanctions antiterroristes", en Europe 2010 (Noviembre, núm. $11)$, pp. 12-14.

SingeR, M. (1995): "Jurisdictional Immunity of International Organizations: Human Rights and Functional Necessity Concerns", en Virginia Journal of International Law (Vol. 36, Issue 1), pp. 53-165.

Slaughter, A. M. (2001), "Globalization, Accountability, and the Future of Administrative Law: The Accountability of Government Networks", en Indiana Journal of Global Legal Studies (Vol. 8, Issue 2), pp. 347-367.

Sousa Santos, B. (2003): Toward a New Legal Common Sense (2nd ed., Cambridge University Press).

STAHN, C. (2008): The Law and Practice of International Territorial Administration Versailles to Iraq and Beyond (Cambridge University Press).

StePhAN, P. B. (1997): "Accountability and International Lawmaking: Rules, Rents and Legitimacy", en Northwestern Journal of International Law and Business (Vol. 17, Issue 2), pp. 681-735.

Tamanaha, B. Z. (2008): "Understanding Legal Pluralism: Past to Present, Local to Global”, en Sydney Law Review (Vol. 30), pp. 375-411.

Teubner, G., Fischer-Lescano, A. (2004): "Regime-Collisions: the Vain Search for Legal Unity in the Fragmentation of Global Law", en Michigan Journal of International Law (Vol. 25, Issue 4), pp. 999-1046. 
Thallinger, G. (2007), "Sense and sensibility of the human rights obligations of the United Nations Security Council”, en Zeitschrift für ausländisches öffentliches Recht und Völkerrecht (Vol. 67, Issue 4), pp. 1015-1040.

Walker, N. (2002): "The Idea of Constitutional Pluralism", en The Modern Law Review (Vol. 65, Issue 3), pp. 317-359.

Wallensteen, P., Staibano, C. (2005): International Sanctions: Between Words and Wars in the Global System (London Routledge/Frank Cass).

Weiler, J. H. H. (1991): "The Transformation of Europe", en The Yale Law Journal (Vol. 100, Issue 8), pp. 2403-2483.

Wellens, K. (2002): Remedies Against International Organizations (Cambridge University Press).

WelLENS, K. (2004): "Fragmentation of International Law and Establishing an Accountability Regime for International Organizations: The Role of the Judiciary in Closing the Gap", en Michigan Journal of International Law (Vol. 25, Issue 4), pp. 1159-1181.

WIDE, R. (2008): International Territorial Administration: How trusteeship and the civilizing mission never went away (Oxford University Press).

Willis, G. L. (2011): "Security Council Targeted Sanctions, Due Process And The 1267 Ombudsperson", en Georgetown Journal of International Law (Vol. 42, Issue 3), pp. 673-745.

Wolfrum, R. (2002): “Article 1", en Simma, B. (ed.), The Charter of the United Nations: A Commentary ( $2^{\text {nd }}$ ed., Oxford University Press), pp. 40-63.

\section{Normas Jurídicas Citadas}

Carta de las Naciones Unidas. San Francisco, 26 de junio de 1945.

Proyecto de artículos sobre Responsabilidad del Estado por hechos internacionalmente ilícitos / Draft Articles on Responsibility of States for Internationally Wrongful Acts (12 diciembre 2001, Resolución de la Asamblea General en su $85^{\text {a }}$ sesión, A/RES/56/83).

Reglamento núm. 1999/1, UNMIK/REG/1999/1, de 25 julio 1999, sobre la autoridad de la administración interina en Kosovo. Título y texto traducidos del original en inglés [(Fecha de consulta: 14 enero 2012). Disponible en <http://www.unmikonline.org/regulations/1999/reg01-99.htm>].

Reglamento núm. 1999/1, UNTAET/REG/1999/1, de 27 noviembre, sobre la autoridad de la Administración de transcición en Timor Oriental. Título y texto traducidos del original en inglés [(Fecha de consulta: 14 enero 2012). Disponible en $<$ http://www.un.org/peace/etimor/untaetR/etreg1.htm>]. 
Reglamento No 1999/24, UNMIK/REG/1999/24, de 12 diciembre 1999, sobre el Derecho aplicable en Kosovo. Título y texto traducidos del original en inglés [(Fecha de consulta: 14 enero 2012). Disponible en <http://www.unmikonline. org/regulations/1999/reg24-99.htm>].

Reglamento No 2000/59, UNMIK/REG/2000/59, de 27 octubre 2000 [(Fecha de consulta: 14 enero 2012). Disponible en <http://www.unmikonline.org/ regulations/2000/reg59-00.htm>].

Reglamento No 2001/9, UNMIK/REG/2001/9, de 15 mayo 2001, por el que se establece el Marco constitucional para el autogobierno provisional, y modificado por el Reglamento núm. 2002/9, UNMIK/REG/2002/9 y por el Reglamento núm. 29/2007, UNMIK/REG/2007/29 [(Fecha de consulta: 14 enero 2012). Disponible en <http://www.unmikonline.org/constframework. htm>].

Resolución No 1.730 (2006), de 19 diciembre, U.N. Doc. S/RES/1730.

Resolución No 1.267 (1999), de 15 de octubre, U.N. Doc. S/RES/1267.

Resolución No 1.904 (2009), de 17 de diciembre, U.N. Doc. S/RES/1904.

\section{JURISPRUDENCIA}

Caso relativo a las condiciones de admisión de un Estado como miembro de las $\mathrm{Na}$ ciones Unidas - artículo 4 de la Carta (1948): Opinión consultiva de la Corte Internacional de Justicia de 28 mayo 1948, en: International Court of Justice Reports 1948, pp. 57-119.

Reparación por daños sufridos al servicio de las Naciones Unidas - caso Bernadotte (1949): Opinión consultiva de la Corte Internacional de Justicia de 11 abril 1949, en: International Court of Justice Reports 1949, pp. 174-220.

Situación jurídica internacional del África Sudoccidental (1950): Opinión consultiva de la Corte Internacional de Justicia de 11 julio 1950, en: International Court of Justice Reports, 1950, pp. 128-219.

Interpretación del Acuerdo de 25 de marzo de 1951 entre la OMS y Egipto (1980): Opinión consultiva de la Corte Internacional de Justicia de 20 diciembre 1980, en: International Court of Justice Reports 1980, pp. 73-98

Caso relativo a las consecuencias jurídicas que tiene para los Estados la continuación de la presencia de Sudáfrica en Namibia (África Sudoccidental), no obstante lo dispuesto en la Resolución 276 (1970) del Consejo de Seguridad (1971): Opinión consultiva de la Corte Internacional de Justicia de 21 de junio de 1971, en: International Court of Justice Reports 1971, pp. 16-66. 
Caso relativo al personal diplomático y consular de los Estados Unidos en Teherán (1980): Sentencia de la Corte Internacional de Justicia de 24 mayo 1980, en: International Court of Justice Reports 1980, pp. 3-46.

M. \& Co. v. Alemania (1990): Decisión de la Comisión Europea de Derechos Humanos de 9 febrero 1990 (recurso núm. 13258/87), en: Yearbook of the European Convention on Human Rights, Vol. 33, 1990, p. 46.

Prosecutor v. Tadi (1995): Decisión del Tribunal Penal Internacional para la antigua Yugoslavia de 2 octubre 1995 (IT-94-1, Decision on the Defence Motion for Interlocutory Appeal on Jurisdiction), disponible en <http://www.icty.org/x/ cases/tadic/acdec/en/51002.htm> (última consulta: 14 enero 2010).

Beer y Regan v. Alemania (1999): Sentencia del TEDH de 18 febrero 1999 (recurso núm. 28934/95), no publicada.

Matthews v. Reino Unido (1999): Sentencia del Tribunal Europeo de Derechos Humanos de 18 febrero 1999 (recurso núm. 24833/94), en: Reports of Judgments and Decisions 1999-I.

Waite y Kennedy v. Alemania (1999): Sentencia del TEDH de 18 febrero 1999 (recurso núm. 26083/94), en: Reports of Judgments and Decisions 1999 I.

Kadi vs. Consejo y Comisión (2005): Sentencia del Tribunal de Primera Instancia de 21 septiembre 2005 (asunto T-315/01) en: Recueil de jurisprudence 2005, p. II-3649.

Bosphorus Hava Yolları Turizm ve Ticaret Anonim irketi v. Ireland (2005): Sentencia del Tribunal Europeo de Derechos Humanos de 30 junio 2005 (recurso núm. 45036/98) en: Reports of Judgments and Decisions 2005-VI.

Behrami v. Francia y Saramati vs. Francia, Alemania y Noruega (2007): Decisión del Tribunal Europeo de Derechos Humanos de 2 mayo 2007 (recursos núm. 71412/01 y 78166/01), no publicada.

Kadi y Al Barakaat International Foundation v. Consejo (2008): Sentencia del Tribunal de Justicia de las Comunidades Europeas de 3 septiembre 2008 (asuntos acumulados C-402/05 P y C-415/05 P) en: Recueil de jurisprudence 2008, p. I-6351.

\section{INFORMES}

Biersteker, T. (2001): Targeted Financial Sanctions. A Manual for Design and Implementation. Contribution from the Interlaken Process (Providence, Brown University).

Bossuyt, M. (2000): The Adverse Consequences of Economic Sanctions on the Enjoyment of Human Rights. Review of Further Developments in Fields with Which the Subcommission Has Been or May Be Concerned (Informe presentado 
ante el Consejo Económico y Social de la ONU, 21 junio 2000, E/CN.4/ Sub.2/2000/33).

Brzoska, M. (2001): Design and Implementation of Arms Embargoes and Travel and Aviation Related Sanctions: Results of the "Bonn-Berlin Process" (International Center for Conversion, Bonn).

CAmeron, I. (2002): Report to the Swedish Foreign Office on Legal Safeguards and Targeted Sanctions (Stockholm, SPITS) [(Fecha de consulta: 14 enero 2011). Disponible en <http://www.smartsanctions.se/Litterature.htm>].

Cameron, I. (2006): The European Convention on Human Rights, Due Process and United Nations Security Council Counter-Terrorism Sanctions (Strasbourg, Council of Europe, 6 febrero).

Comisión de Derecho Internacional (2006): Informe de la Comisión de Derecho Internacional de Naciones Unidas en su $58^{\circ}$ período de sesiones (1 de mayo a 9 de junio y 3 de julio a 11 de agosto de 2006, U.N. Doc. A/61/10/2006).

Comisión de Derecho Internacional (2009): Informe de la Comisión de Derecho Internacional de Naciones Unidas en su $61^{\circ}$ período de sesiones ( 4 de mayo a 5 de junio y 6 de julio a 7 de agosto de 2009, U.N. Doc. A/64/10/2009).

Comisión de Derecho Internacional (2011): Informe de la Comisión de Derecho Internacional de Naciones Unidas en su $63^{\circ}$ período de sesiones - Texto y título de los proyectos de artículo 1 a 67 sobre Responsabilidad de las organizaciones internacionales aprobados en segunda lectura por el Comité de Redacción en 2011 (26 de abril a 3 de junio y 4 de julio a 12 de agosto de 2011, U.N.Doc A/CN.4/L.778).

Comité de Derechos Humanos (2006): Informe del Comité de Derechos Humanos del Pacto Internacional sobre derechos civiles y politicos de 14 agosto 2006 sobre la Administración Interina de la Misión de Naciones Unidas en Kosovo (14 agosto 2006CCPR/C/UNK/CO/1, GE.06-43691 (E) 080906).

Consejo de Seguridad de la ONU (2004): Comunicado de Prensa del Consejo de Seguridad SC/8192 de 20 septiembre [(Fecha de consulta: 14 enero 2011). Disponible en: <http://www.un.org/News/Press/docs/2004/sc8192. doc.htm>].

InTERNATIONAL LAW COMMISSION (2006): Report on the "Fragmentation of International Law: Difficulties arising from the Diversification and Expansion of International Law" before the General Assembly (18 julio, U.N. Doc.A/CN.4/L.702, GE.06-62863 [E] 200706).

International LaW Commission (2011): Statement of the Chairman of the Drafting Committee, 3 junio [Fecha de consulta: 14 enero 2012). Disponible en: $<$ http://untreaty.un.org/ilc/guide/9_11.htm>]. 
Secretario General de la ONU (1999): Informe sobre la Misión de Administración Provisional de las Naciones Unidas en Kosovo (12 julio, UN Doc. S/1999/779).

SeCretario General de la ONU (1999): Observancia del derecho internacional humanitario por las fuerzas de las Naciones Unidas (de 6 agosto 1999, Preámbulo del Boletín del Secretario General, UN Doc. ST/SGB/1999/13).

SeCurity Council (2010): Report of the Analytical Support and Sanctions Monitoring Team on the outcome of the review described in paragraph 25 of resolution 1822 (2008) submitted pursuant to paragraph 30 of resolution 1904 (2009) (29 September, S/2010/497).

Venice Commission (2004): Opinion on Human Rights in Kosovo: Possible establishment of review mechanisms (Opinion 280/2004, Strasbourg 11 octubre, CDL-AD(2004)033).

WallensteEn, P., STAibANO, C. (2003): Making targeted sanctions effective: guidelines for the implementation of UN policy options (Stockholm, Elanders Gotab). 
